\title{
River Restoration Effects on Steelhead Populations in the Manistee River, Michigan: Analysis Using an Individual-Based Model
}

\author{
JEFFREY A. TYLER* \\ Fisheries Projections, 307 Old Mountain Road, Farmington, Connecticut 06032, USA
}

\section{EDWARD S. RUTHERFORD}

Institute for Fisheries Research, School of Natural Resources and Environment, University of Michigan, 218 Museum Annex Building, 1109 North University Avenue, Ann Arbor, Michigan 48109-1084, USA

\begin{abstract}
The Manistee River, Michigan, watershed includes two dams as well as residential and agricultural development, and the river itself contains a sizeable population of steelhead Oncorhynchus mykiss that supports a valuable recreational fishery. Restoration of the Manistee River and its flow regime may improve steelhead habitat and the fishery. We developed an individual-based model of steelhead in the Manistee River to assess the population effects of changes in the number of spawners, water discharge from Tippy Dam, and water temperature. The model follows steelhead from spring spawning to the end of the growing season in early fall and depicts the river environment as a series of cells that vary in dimension, water velocity, and substrate. Simulated water discharge, temperature, and prey availability changed daily based on observations from Tippy Dam. Empirically based models describe individual steelhead fry and parr foraging and growth. In the model, steelhead select habitats and maximize individual fitness while accounting for dominance and the availability of feeding territories. We calibrated the model to replicate fish growth, mortality, and population size. Simulation experiments manipulated the number of spawning females, water discharge, and water temperature. The results suggest that Manistee River steelhead incur density limitations in the fry and parr stages and that water discharge and temperature changes affect the number and biomass of parr. Increasing river discharge negatively affected parr numbers and weight. Decreasing maximum midsummer temperature increased parr numbers and weight when the change was large, but otherwise had little effect. These results indicate that restoration of the natural flow regime in the Manistee River will probably increase the quality of the habitat for steelhead but that density limitations in the fry and parr stages may ultimately limit population growth.
\end{abstract}

Human activity has greatly altered rivers and their fish populations. The construction of dams and changes in land use activities surrounding rivers, including agriculture, forestry, and urbanization, have affected water availability, velocity, temperature, sediment transport, and other physical and chemical factors in many rivers (Poff et al. 1997; Lytle and Poff 2004). Dam removal has a large number of advocates and has received much attention of late as one of the most important tools for mitigating anthropogenic damage to rivers (Hart et al. 2002). However, not all dams can or should be removed (Babbitt 2002), and dam removal is not the only important problem for fish populations. Alterations to river flow regimes have important direct and indirect effects on fish populations (Poff et al. 1997; Freeman et al. 2001; Bunn and Arthington 2002; Osmundson et al. 2002).

\footnotetext{
* Corresponding author: jeffrey.a.tyler@comcast.net
}

Received June 21, 2006; accepted July 6, 2007

Published online November 29, 2007
Populations of introduced steelhead (anadromous rainbow trout Oncorhynchus mykiss) support an important fishery in the Great Lakes and reproduce naturally in a number of Great Lakes tributaries (Biette et al. 1981). Although natural reproduction occurs in many tributaries, only $10-30 \%$ of the Lake Michigan steelhead harvest is composed of wild fish, and the rest is supported by stocking (Rand et al. 1993). The Manistee River, Michigan, is home to a sizeable steelhead run of approximately 20,000 adults and contains two large hydroelectric dams that affect the river's flow regime and the quantity and quality of habitat available for steelhead (Horne et al. 2004). Tippy Dam, the dam closest to the river's mouth, presents an impassable barrier to steelhead spawning migrations, and operation of the dam has a strong effect on flow regime and water temperature in the steelheadaccessible section (Rozich 1998).

Because the steelhead fishery in the Manistee River is important economically, mitigating the effects of human alteration to the river has high priority. Proposed tools for improving the quality of the 


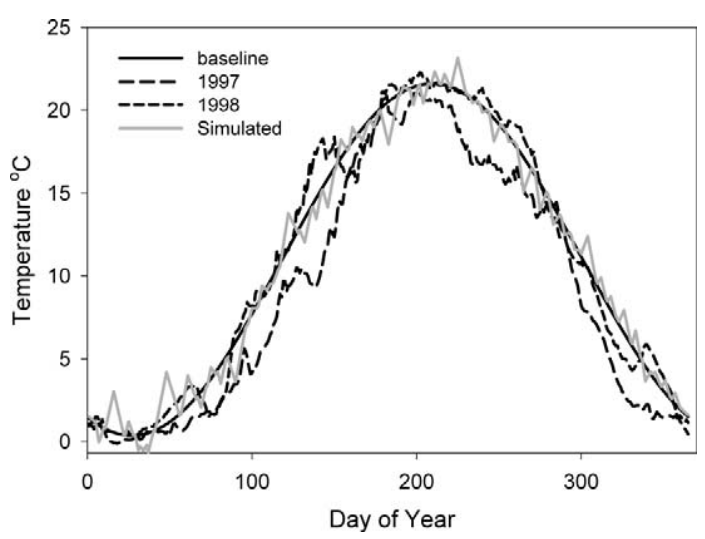

FIGURE 1.-Actual (1997-1998) and simulated water temperatures at Tippy Dam on the Manistee River, Michigan. Also shown is the simulated long-term mean temperature "baseline" used in a steelhead population model.

Manistee River for steelhead include altering the flow regime and water temperature. In 1990, Tippy Dam changed from a peaking hydropower operation, which generated 10-year flood and drought events twice daily in the river, to a run-of-the-river operation that produced flows consistent with naturally occurring seasonal patterns. Dam operators are able to make further alterations to overall water releases in a manner that may affect steelhead production. In addition, Tippy Dam affects the temperature of the water in the river (Rozich 1998). Tippy Dam withdraws water from its reservoir above the thermocline, thus sending warm water down the Manistee River. Alteration of the dam to a bottom-withdraw system could have a notable effect on the river's water temperature and could greatly improve the river's capacity to support steelhead populations (Horne et al. 2004).

We created an individual-based model of young-ofthe-year (age-0) steelhead in the Manistee River to examine the potential effects of changes in the management of Tippy Dam and the steelhead population itself that cannot be easily explored through direct field measurement or experimentation. The model follows steelhead from spawning to the end of the first growing season in early October and uses the number of individuals and biomass as measures of population recruitment. The model environment generally replicates conditions in the spawning area of the Manistee River just downstream of Tippy Dam. The model simulations explore the change in steelhead recruitment caused by changes in water temperature, total discharge, and the number of spawning females. We select these factors because they are the most practical management options for improving steelhead recruitment in the river.

\section{Model Description}

\section{Methods}

The model of steelhead populations in the Manistee River has two distinct components: the river and the fish population. Although the modeled environment is based on the Manistee River, the depiction of the river is somewhat generic. We use site-specific data to determine relationships regarding dimensions, substrate characteristics, water velocity, and temperature, but specific cells do not correlate to specific geographical locations in the Manistee River itself. Likewise, the steelhead model draws on data from steelhead in the Great Lakes region and, where possible, the Manistee River specifically, but not all data come from steelhead in the region. Some mechanistic relationships were adopted from studies of steelhead life stages and habitats in western or southern rivers and from laboratory experiments.

\section{Manistee River Environment}

Key features of the model environment include water temperature, discharge, and flow, hours of daylight, prey densities, cell dimensions (depth, width, and distance), steelhead feeding stations, and substrate characteristics. Many of these features are determined from data specific to the Manistee River; while those for which site-specific data are not available are determined from data collected at similar rivers. The model environment consists of 100 cells; some features have unique values in each cell, and some features are common among all cells (i.e., water temperature, stream discharge, daylight hours, and prey densities).

Environmental features common to all river cells.The water temperature for the model is based on data from Tippy Dam collected during 1997-1998 and does not vary among cells. A mean temperature $(T)$ function was fit to the data (Figure 1) using a sine-cosine function, namely,

$$
\begin{aligned}
T= & a-[b \times \cos (0.0172 \times \text { day })] \\
& -[c \times \sin (0.0172 \times \text { day })] .
\end{aligned}
$$

The parameter values for equation (1) that produce baseline temperatures are $a=11, b=9.5$, and $c=4.75$. Daily variance from the mean daily water temperature was determined using a method similar to that described by Rose et al. (1996). This method computes a maximum deviation from the long-term mean (positive or negative) and the duration of that deviation. The maximum deviation from the mean occurs at the midpoint of the period during which 
temperature deviates from the long-term mean. Thus, the temperature on that day is the long-term mean temperature for the day based on equation (1) plus the maximum deviation from the mean (positive or negative) during the period of temperature deviation. To obtain temperatures for the other days of the deviation period, we use simple linear interpolation between the day with maximum deviation from the mean and the endpoints of the deviation period. At the end of the period of deviation from the long-term mean, the temperature value returns to the long-term mean.

We use simulated temperatures rather than actual temperatures in the model so that we could establish a baseline simulation set for comparisons. Actual field temperatures have idiosyncrasies (e.g., a run of high or low temperatures on specific days or weeks), and each set of field-measured temperatures includes such idiosyncrasies and differences in the mean temperature. Simulated temperatures allow us to control mean temperature and include daily stochasticity without including specific idiosyncratic patterns that may occur in field data.

The method for simulating daily water discharge $(Q$ $\left.\left[\mathrm{m}^{3} / \mathrm{s}\right]\right)$ in the model is similar to that for simulating temperature, except that it reflects the particular ways in which the flow varies. Discharge simulation begins with the mean daily discharge from Tippy Dam over a 9-year period (1990-1998) and then adds random deviations from the mean. The maximum deviation $\left(Q_{\Delta \max }\right)$ and duration of deviations $\left(Q_{\text {dur }}\right)$ from the 9-year mean are from an analysis of the deviations from the mean discharge (U.S. Geological Survey [USGS], unpublished data). For each deviation from the mean, $Q_{\Delta \max }$ is drawn from a cumulative distribution function of the maximum deviations from the mean for each run of discharge values that differ from the 9-year mean. A regression relationship between maximum deviation and duration of the deviation is used to find $Q_{\text {dur }}$. Different regressions were constructed for positive and negative $Q_{\Delta \max }$ values, because deviations below and above base flow result from quite different hydrological processes. The day on which $Q_{\Delta \max }$ occurs is $0.35 \cdot Q_{\text {dur }}$ for positive deviations and $0.65 \cdot Q_{\text {dur }}$ for negative deviations. We use a linear interpolation to compute discharge values for the period of $Q_{\text {dur }}$ with increasing slope. We use an exponential decay function to interpolate discharge values for the period of $Q_{\text {dur }}$ with declining discharge, which occurs either after $Q_{\Delta \max }$ for positive values or at the beginning of $Q_{\text {dur }}$ for negative values of $Q_{\Delta \max }$. During the period of declining discharge, the discharge for a specific day $\left(Q_{\text {day }}\right)$ is the mean $\left(\bar{Q}_{\text {day }}\right)$ times a fraction of $Q_{\Delta \max }$, that is,
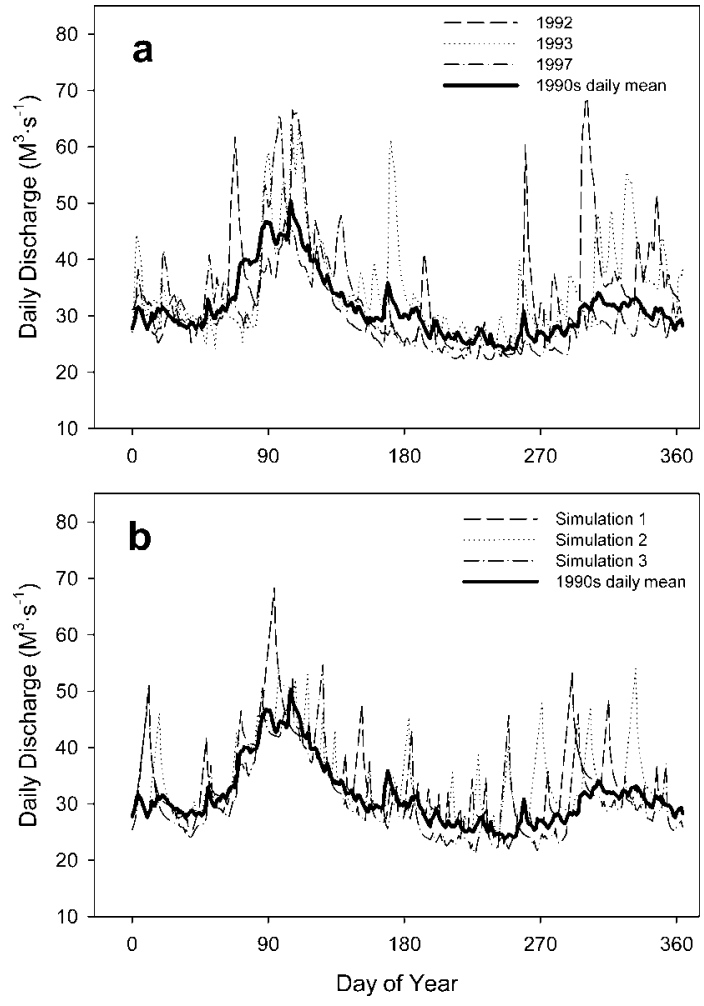

Figure 2.-Daily water discharge from Tippy Dam. Panel (a) shows the actual discharge in three randomly selected years during the period 1990-1998 and panel (b) three randomly selected simulations of the discharge that were used in a steelhead population model. The mean daily discharge from the 1990s is also shown in each panel.

$$
\begin{aligned}
Q_{\text {day }} & =\bar{Q}_{\text {day }}+Q_{\Delta \max } \cdot Q_{\mathrm{fac}}, \\
Q_{\mathrm{fac}} & = \begin{cases}e^{Q_{\mathrm{day}} \theta} & \text { for } Q_{\Delta \max }>0 \\
1.0-e^{Q_{\mathrm{day}} \theta} & \text { for } Q_{\Delta \max }<0,\end{cases} \\
\theta & =-0.009-\left(4.32 / Q_{\text {day }}\right),
\end{aligned}
$$

where $e$ is the base of natural logarithms. Simulations using this algorithm generate daily discharge values that reasonably replicate the data from Tippy Dam during 1990-1998 (Figure 2). Because the area of the Manistee River modeled here is only the 5-km section immediately downstream of the dam, water discharge is assumed to be constant among cells in the simulated river environment.

Daylight hours (DL) determine the amount of time that fish may forage for food. The DL variable follows a function appropriate for locations at $44.25^{\circ} \mathrm{N}$ (Brock 1981), where the Manistee River lies, that is, 

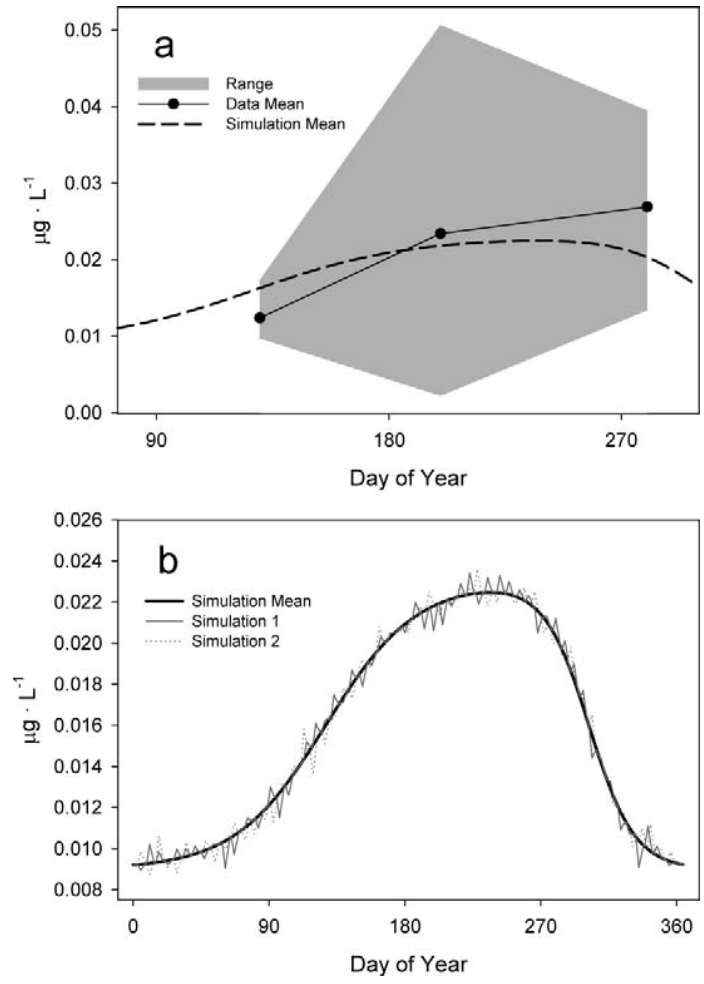

FIGURE 3.-Daily prey density $(\mu \mathrm{g} / \mathrm{L}$ ) available to steelhead fry and parr in the Manistee River. Panel (a) shows the actual means and range of the data and a simulated mean used in a steelhead population model. Panel (b) shows two randomly selected simulations and the long-term simulation mean, demonstrating that each simulation embodied some random variation from the mean.

$$
\begin{aligned}
\mathrm{DL}=\frac{24}{\pi} \times \arccos \{ & -\tan \left(\frac{\pi}{180} \times \text { lat }\right) \\
& \times \tan \left[\frac{\pi}{180}\right. \\
& \left.\left.\times 23.45 \sin \left(\frac{2 \pi(284+\text { day })}{365}\right)\right]\right\} .
\end{aligned}
$$

As described in detail below, steelhead fry and parr feed on drifting prey. Prey densities follow a function calibrated to data collected in the Muskegon River, Michigan, about $130 \mathrm{~km}$ (80 mi) south of the Manistee River. Because the data used for the model do not come from the Manistee River, we model prey density (PD) in the aggregate as micrograms per liter rather than attempting to replicate the species and sizes of macroinvertebrates in the river.

The prey data from the Muskegon River come from samples of macroinvertebrates collected from the river substrate (Godby 2000). The invertebrate samples were collected at six sites in the summer and fall of 1998 and spring of 1999. To obtain macroinvertebrate density $(\mu \mathrm{g} / \mathrm{L})$ in the drift, we assumed that $10 \%$ of the macroinvertebrates in the substrate will enter the drift on a given day. The amount of substrate varies with river width, which itself is a function of daily discharge (see below). Computing the amount of area from which macroinvertebrates may emerge to enter the drift and multiplying by the density gives the total number of macroinvertebrates entering the drift each day. The volume of water passing through the river in a day is determined by discharge. Assuming an average mass of $0.3 \mu \mathrm{g}$ for individual macroinvertebrates (C. Riseng and M. Wiley, University of Michigan, Ann Arbor, unpublished data) vulnerable to fry and parr foraging allows us to compute drift density. We use minimum and maximum densities in the substrate as well as minimum and maximum discharge values during each season (spring, summer, fall) to compute the range of prey densities that could be expected (Figure 3a).

Simulated PD follows a function that allows numbers to increase in the spring and decline in the fall, namely,

$$
\begin{aligned}
\mathrm{PD}=1 & +\left\{1-\frac{1}{1+\exp [-(\text { day }-127) / 30]}\right\} \\
& \times\left\{1-\frac{1}{1+\exp [-(\text { day }-302) / 15]}\right\} .
\end{aligned}
$$

The simulated PDs fall well within the range of values observed in the data (Figure 3a). In each specific simulation, prey densities vary from the mean using the same algorithm as that used to create variability in water temperature (Figure 3b).

Environmental features that vary among cells.-The spatial component of the model environment depicts the river as a linear series of cells with independent cell dimensions. The widths and depths of the cells are based on data from two transects of an instream flow incremental methodology (IFIM) study of the Manistee River (Ichthyological Associates 1990). We linked the width and depth of each cell to the discharge from Tippy Dam using relationships derived from the IFIM data. We use only two transects to describe the depth and width of the simulated stream because the IFIM study only sampled these two transects in the section of the Manistee River downstream of Tippy Dam, which is the environment that the model attempts to replicate. For each IFIM transect, the relationship between depth $(D[\mathrm{~cm}])$ and discharge is described as follows:

$$
D=a Q^{b}+c .
$$

For IFIM transect $1, a=17.75$ and $b=0.456$; for IFIM transect 2, $a=31.11$ and $b=0.302$. For both transects, 
$c=15(\mathrm{~cm})$ and is a calibrated factor to adjust computed water velocities in the model environment to fit with the water velocities measured in the Manistee River. When assigning a depth to each cell, we randomly determined which of the two depth relationships the model would use, computed the depth by means of equation (7), and then introduced random variation to produce a $20 \%$ coefficient of variation (CV; variance divided by mean) in depth. The width of each cell $(W[\mathrm{~cm}])$ was determined directly from depth using relationships determined from the same IFIM transect data, namely,

$$
W=a D^{b} .
$$

The parameters ( $a$ and $b$ ) for equation (8) are 4,577.92 and 0.083 for IFIM transect 1 and 316.09 and 0.632 for IFIM transect 2. The mean distance of the cells was set to $50 \mathrm{~m}$; the actual distance of each cell was determined from a random normal distribution with a $10 \% \mathrm{CV}$.

Each cell has its own water velocity and substrate that depend on the cross-sectional area of the cell and stream discharge. Average water velocity $\left(V_{\text {avg }}\right)$ in each cell is computed by dividing the discharge $\left(\mathrm{m}^{3} / \mathrm{s}\right)$ by the cross-sectional area of the cell $\left(\mathrm{m}^{2}\right)$. The substrate in each cell is based on water velocity and a random variant. Substrate itself is a measure of the fraction of the stream bottom that is cobble or gravel and is affected by depth (17\%), velocity (33\%), and random variation in local geology $(50 \%)$. Using IFIM data on substrate and depth in the Manistee River, we model the depth component of the percentage of the substrate that is gravel (SG) as follows:

$$
\mathrm{SG}=3.95+\frac{66.44}{1+\exp \left(\frac{D-1.789}{0.144}\right)}
$$

We represent the effect of a weighted average of the water velocity in a cell over the last $5 \mathrm{~d}$ on substrate with the following equation:

$$
\mathrm{SG}=81.24+37.37 \cdot \log _{e}\left(V_{\mathrm{wavg}}\right),
$$

where $V_{\text {wavg }}$ is the weighted average of water velocity and is determined as follows:

$$
V_{\text {wavg }}=\left(V_{\text {avg }} \times 0.5\right)+\left(V_{\text {wavg,day }-1} \times 0.5\right),
$$

where $V_{\text {wavg,day-1 }}=$ the weighted average velocity for the cell the previous day. This computation method reflects a strong contribution to $V_{\text {avg }}$ by the currently measured velocity and a negligible contribution by velocity measured $6 \mathrm{~d}$ previously. The amount of substrate composed of fine sediment (FINE) is a calibrated function of SG, namely,

$$
\mathrm{FINE}=\exp [-2-(13.863 \times \mathrm{SG})] .
$$

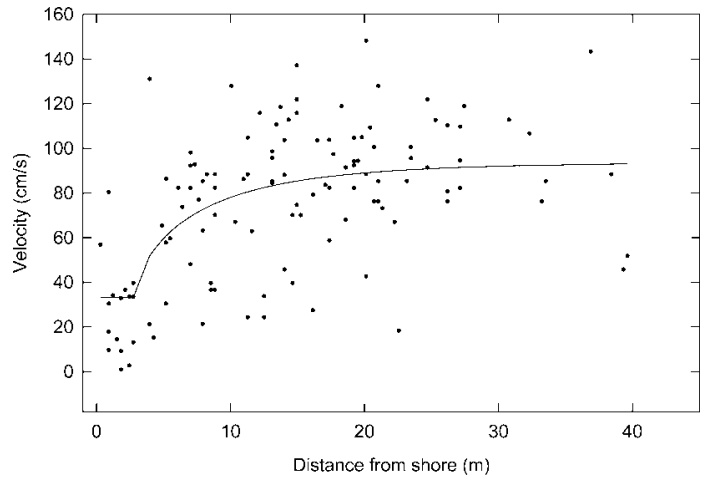

FIGURE 4.-Relationship between water velocity and distance from shore in the Manistee River. The solid line indicates the mean velocity in the main stem.

In addition to gravel composition, the composition of the substrate in each cell includes the number of feeding stations for the fry $\left(\mathrm{SN}_{\text {fry }}\right)$ and parr $\left(\mathrm{SN}_{\text {parr }}\right)$ stages. The number of feeding stations in each cell is based on the mean densities of fry and parr (Grant and Noakes 1987; Grant and Kramer 1990; Grant et al. 1998) and the area that fry and parr use for feeding. Densities are about $100 \mathrm{fish} / \mathrm{m}^{2}$ for fry and about 10 fish $/ \mathrm{m}^{2}$ for parr (Grant and Noakes 1987). Fry and parr are limited to feeding in the margins near the bank of the stream. Fry feeding stations exist in the area within $1.5 \mathrm{~m}$ of the riverbank, and parr feeding stations are found in the area within $3.0 \mathrm{~m}$ of the riverbank. Feeding station numbers for fry and parr are computed by multiplying the density of feeding stations and the area including these stations for each life stage in all cells. Velocity of the water in the margin areas $\left(V_{\text {margin }}\right)$ affects the feeding of fry and parr (described below). Water velocity data from the Manistee River show that the velocity in the margins $(33.96 \mathrm{~cm} / \mathrm{s})$ is $40 \%$ of the average velocity in the main stem $(83.76 \mathrm{~cm} / \mathrm{s})$ (Figure 4).

\section{Steelhead Population}

The model for steelhead begins at spawning in the spring and ends at the first growing season in the fall. The simulation begins with a population of spawning females and then follows the offspring through the egg, alevin, fry, and parr stages. The model follows redd cohorts in the egg and alevin stages and individuals at the beginning of the fry stage.

Spawning rules.-The population of spawning females has a mean length of $680 \mathrm{~mm}$ and a $10 \%$ $\mathrm{CV}$. The area used for each redd $\left(A_{\text {spawn }}\left[\mathrm{cm}^{2}\right]\right)$ is based on length $(L[\mathrm{~mm}])$ of the spawning female (Crisp and Carling 1989; Clark and Rose 1997), that is, 


$$
A_{\text {spawn }}=0.0114 \times \pi L^{2.137} .
$$

The number of eggs per redd $\left(N_{\text {egg }}\right)$ is based on spawner length (E.S.R., unpublished data) for steelhead in the Little Manistee River as described by the equation

$$
N_{\text {egg }}=171.89(L / 10)-6,466 .
$$

Spawning for steelhead in Great Lakes tributaries begins in mid-March, lasts for 6 weeks, and peaks at 3 weeks (Biette et al. 1981). Spawning females in the model are assigned a spawning day selected from a triangular distribution ranging from day 80 to day 140 with a peak at day 100 . Spawning occurs only at temperatures between $2^{\circ} \mathrm{C}$ and $14^{\circ} \mathrm{C}$.

There are some constraints on the cells in which females can spawn. Such cells must have a minimum depth of $60 \mathrm{~cm}$ and a maximum $V_{\text {avg }}$ of $75 \mathrm{~cm} / \mathrm{s}$ (Van Winkle et al. 1998). The substrate must have an SG value of 10-50\% (Workman 2002). Females may only spawn in cells that have area available. Cells that fit the velocity and substrate criteria have $20 \%$ of their area available for spawning (Workman 2002). If the cell selected is filled, then the spawning female overlays an existing redd selected at random in the cell, thereby killing the eggs and alevins in the existing redd.

Egg and alevin development and mortality.-The model follows steelhead egg and alevin stages as redd cohorts. All individuals in the redd develop and die at the same rate. Development is based on water temperature (Regier et al. 1990; Kamler 1992). The method of modeling development is similar to that used in other models (Rose et al. 1996; Clark and Rose 1997). The eggs and alevins in each redd achieve some fraction of their total development every day (FDEV) based on the water temperature, that is,

$$
\mathrm{FDEV}=1 /\left(d a \times T^{d b}\right) .
$$

For eggs, $d a=150$ and $d b=-0.6$ (Regier et al. 1990); for alevins, $d a=50$ and $d b=-0.75$ (Kamler 1992). Eggs and alevins complete each stage when the sum of fraction of development for the stage reaches a value of 1.0. At that point, eggs graduate to the alevin stage and alevins graduate to the fry stage.

Mortality for eggs and alevins occurs through the effects of predation and variation in water velocity. Daily mortality from predation for eggs and for alevins is $2.25 \%$. Low water velocity can result in deposition of fine sediment and silt into redds, which increases egg mortality. Daily mortality of eggs and alevins resulting from siltation effects $\left(\mu_{\text {fine }}\right)$ increases as FINE increases (Meyer 2003), that is,

$$
\mu_{\text {fine }}=\left[(6.95 \times \mathrm{FINE})-\left(20.5 \times \mathrm{FINE}^{2}\right)\right] / 35 \text {. }
$$

High water velocities can cause a reduction of eggs or alevins as a result of redd scouring. We developed a relationship linking scour mortality for eggs and alevins $\left(\mu_{\text {scour }}\right)$ to the cell's values for $V_{\text {avg }}, S G$, and $D$. Lapointe et al. (2000) provided the following relationship between bed substrate mobility ratio (MR) and $\mu_{\text {scour }}$ :

$$
\mu_{\text {scour }}=(0.3 \times \mathrm{MR})-0.2 \text {. }
$$

The mobility ratio is a function of the water's shear force $(\mathrm{SF})$, substrate size $\left(D_{50}\right.$, i.e., the diameter of $50 \%$ of the substrate), and critical shear ( $\Theta$; here, we assume $\Theta=0.06$; the equation is

$$
\mathrm{MR}=\mathrm{SF} /\left(16.18 \times D_{50} \times \Theta\right) .
$$

Shear force is a function of $V_{\text {avg }}, D$, and water density ( $\rho$; here, we assume $\rho=1,000)$; the equation is

$$
\mathrm{SF}=\left\{\frac{V_{\mathrm{avg}}-0.01}{5.75\left[\log _{e}\left(\frac{D}{100} \times 0.4\right)+0.699\right]}\right\}^{2} \times \boldsymbol{\rho} .
$$

Finally, we estimate $D_{50}$ from SG using information from Church et al. (1987) and Consumer's Energy Corporation (unpublished data); the equation is

$$
D_{50}=\left[0.33+\left(85 \times \mathrm{SG}^{1.75}\right)\right] / 1,000 .
$$

Fry and parr foraging and growth.-The model follows steelhead through the fry and parr stages as true individuals. The same functions determine foraging and growth for both fry and parr stages, but the parameters for the two stages differ.

Fry begin at a length of $20 \mathrm{~mm}$ when they graduate from the alevin stage. Individuals graduate from the fry to the parr stage when they reach $40 \mathrm{~mm}$. Within each stage, some individuals obtain feeding stations (station holders), while others cannot (floaters). The model determines which individuals are station holders based on a weight-based dominance ranking in each cell. We use weight as the determinant based on studies with rainbow trout (McCarthy et al. 1992) and masu salmon O. masou (Nakano 1995). Individuals in each stage within a cell are ranked according to weight. The number of fry or parr with a rank no more than $\mathrm{SN}_{\text {fry }}$ or $\mathrm{SN}_{\text {parr }}$ receive feeding stations. The remaining individuals in each class are floaters.

Foraging for station holders assumes that individuals are drift feeders that feed on food items passing within their reactive distance (RD) while they hold position and that feeding occurs during daylight. Consumption $(C)$ is the product of the volume searched (VS), PD, 
and the probability of capture $\left(P_{\text {cap }}\right)$, that is,

$$
C=\mathrm{VS} \times P_{\text {cap }} \times \mathrm{PD} .
$$

The volume searched for each individual is computed as a cylinder with radius equal to the RD of the individual and distance equal to the linear measure of water that passes through the margin areas (Gerritsen and Strickler 1977; Godin and Rangeley 1989; Hughes and Dill 1990). We assume that RD equals fish length, with a maximum of $50 \mathrm{~mm}$, that is,

$$
\mathrm{VS}=\pi \times \mathrm{RD}^{2} \times V_{\text {margin }} \times \mathrm{DL} .
$$

The $P_{\text {cap }}$ varies with water velocity and temperature based on a function derived from data reported by Hill and Grossman (1993):

$$
\begin{aligned}
P_{\text {cap }}= & \frac{0.985-0.048 V_{\text {margin }}+0.00056 V_{\text {margin }}^{2}+0.0046 T}{1-0.045 V_{\text {margin }}+0.0013 V_{\text {margin }}^{2}+0.0063 T} \\
& \times 0.1
\end{aligned}
$$

Foraging differs between floaters and station holders in thatfloaters encounter fewer prey items and are subject to local density effects to which station holders are immune. Consumption by floaters $\left(C_{\text {float }}\right)$ is computed by the same method as that for station holders (equation 21) except that it is multiplied by a penalty $\left(\rho_{\text {cons, } S}\right)$ subject to the effects of local floater density (FD), that is,

$$
\boldsymbol{\rho}_{\mathrm{cons}, S}=a_{\boldsymbol{\rho} c, S}-b_{\boldsymbol{\rho} c, S}\left(\mathrm{FD}_{S, i} / \mathrm{FD}_{S, i, \mathrm{CRIT}}\right),
$$

where $\rho_{\text {cons, } S}$ is the consumption penalty for floaters in each stage, $S$ is stage (fry or parr), $i$ is the cell number, and CRIT is the critical value for FD. The parameters in the equation take the following values: $a_{\rho c \text {,fry }}=0.9$, $a_{\rho c \text {,parr }}=0.975 ; b_{\rho c \text {,fry }}=0.3$, and $b_{\rho c \text {,parr }}=0.325$. The value of $\rho_{\text {cons,fry }}$ is constrained to $0.60-0.10$, and $\rho_{\text {cons,parr }}$ is constrained to $0.65-0.10$. The FD $_{S, i, \text { CRIT }}$ equals the number of feeding stations in each cell $i$ for each of the two stages; it assumes that cells with a higher number of feeding stations can also support a higher number of floaters before FD begins to affect $C$. For all fish, $C$ cannot exceed the maximum consumption $\left(C_{\max }\right)$ determined by bioenergetics models (Hanson et al. 1997).

The growth of fry and parr follows the common bioenergetics model first developed by Kitchell et al. (1977) and recently summarized by Hanson et al. (1997). The specific equations used for the bioenergetics calculations can be found in Hanson et al. (1997). The bioenergetics parameters used here are those developed for age-0 steelhead (Tyler and Bolduc, in press.). The modeling of growth $(G)$ uses a mass balance approach, namely,

$$
G=C-(R+F+U+\mathrm{SDA}),
$$

where $R$ is respiration, $F$ is egestion, $U$ is excretion, and SDA is specific dynamic action. To convert fry or parr weight into length, the model uses a length-weight relationship compiled from multiple sources (Clark and Rose 1997), that is,

$$
L=46.73 W^{0.337} .
$$

The weight and length of fish are partly decoupled in that fish may lose weight if energetic costs exceed $C$, but they may not lose length because skeletal structure is conserved.

Fry and parr mortality.-Mortality for fry and parr may come from three sources: predation, starvation, or temperature extremes. Predation mortality $\left(\mu_{\text {pred }}\right)$ is a random event with a probability based on length, that is,

$$
\mu_{\text {pred }}=0.0375+3.0 / L^{1.9}
$$

Floaters incur an increased predation rate that is computed as the base rate $\left(\mu_{\text {pred }}\right)$ times a penalty $\left(\rho_{\text {mort }, S}\right)$, where

$$
\boldsymbol{\rho}_{\text {mort }, S}=2\left(\mathrm{FD}_{S, i} / \mathrm{FD}_{S, i, \mathrm{CRIT}}\right)
$$

and has a lower bound of 2.0. The base function for mortality (equation 27) was drawn from a composite of information from Van Winkle et al. (1998) and Clark and Rose (1997) and was calibrated to produce an average daily mortality rate $(Z)$ similar to that found in the Manistee, Little Manistee, and Muskegon rivers (Godby 2000; Horne et al. 2004).

Fry and parr can incur starvation mortality. If their growth trajectory becomes negative to the extent that their body weight falls to $50 \%$ of that expected for an individual of their length, the model assumes that they starve and removes them from the population.

High temperatures also cause mortality in steelhead fry and parr. Using data presented by Hokanson et al. (1977), we derived the following temperature-based mortality rate $\left(\mu_{\text {temp }}\right)$ for fry and parr:

$$
\begin{aligned}
\mu_{\mathrm{TEMP}}= & -0.15 \\
& +0.5\left[\frac{1}{1+(T / 22)^{-9.75}}\right]\left[\frac{1}{1+(L / 45)^{5.0}}\right] .
\end{aligned}
$$

Hokanson et al. (1977) found that smaller fish incur a greater risk of mortality from high temperatures than do larger fish and that the risk increases with temperatures above $22^{\circ} \mathrm{C}$.

Fry and parr movement.-The movement of fry and parr individuals among cells in the simulated Manistee 
TABLE 1.-Mean results from five baseline simulations for steelhead egg and alevin stages used in the model calibration of a population model.

\begin{tabular}{lccccc}
\hline Stage & $\begin{array}{c}\text { Duration } \\
\text { (d) }\end{array}$ & $\begin{array}{c}\text { Daily mortality } \\
\text { (fish/d) }\end{array}$ & $\begin{array}{c}\text { Fraction } \\
\text { surviving stage }\end{array}$ & $\begin{array}{c}\text { Fraction of mortality } \\
\text { from predation }\end{array}$ & $\begin{array}{c}\text { Fraction of mortality } \\
\text { from scour-siltation }\end{array}$ \\
\hline Egg & 34.6 & 0.025 & 0.422 & 0.986 & 0.014 \\
Alevin & 6.9 & 0.024 & 0.848 & 0.999 & 0.001 \\
\hline
\end{tabular}

River environment uses a fitness-maximizing algorithm based on the marginal value theorem (Charnov 1976; Bernstein et al. 1988; Tyler and Rose 1997). The fundamental rule is that individuals should minimize the ratio of mortality risk to growth rate, thereby maximizing long-term growth and survival (Werner and Gilliam 1984; Gilliam and Fraser 1987).

In the model, individual fry and parr move from their current cell based on a rule that minimizes the ratio of predation mortality risk and the proportion of maximum consumption ( $\left.p\left[C_{\text {max }}\right]\right)$, within some bounds. To implement the rule, each individual maintains a weighted average of the previous values of $\bar{\mu}_{\text {pred }}$ and $\bar{p}\left(C_{\text {max }}\right)$. The effects of past values of $\bar{\mu}_{\text {pred }}$ and $\bar{p}\left(C_{\max }\right)$ on current values are scaled by a memory factor $(\delta)$ set at 0.5 to approximate a 5-d memory (Milinski and Regelmann 1985), that is,

$$
\begin{aligned}
\bar{\mu}_{\text {pred,day }} & =\left(\delta \times \bar{\mu}_{\text {pred,day }-1}\right)+(1-\delta) \mu_{\text {pred }} \\
{\left[\bar{p}\left(C_{\max }\right)\right]_{\text {day }} } & =\left[\delta \times \bar{p}\left(C_{\max }\right)_{\text {day-1 }}\right]+(1-\delta) \bar{p}\left(C_{\max }\right) .
\end{aligned}
$$

Using the logic of the marginal value theorem, individuals move from their current cell if the value of $\mu_{\text {pred }} / p\left(C_{\text {max }}\right)$ exceeds that of $\bar{\mu}_{\text {pred }} / \bar{p}\left(C_{\text {max }}\right)$.

The model contains two important exceptions to the above movement rule: (1) floaters should always do better if they can find an available feeding station in a different cell, so all floaters move at the end of the day; and (2) any individual moves if it has lost weight over the previous $5 \mathrm{~d}$.

For individuals that move among cells, the rule for the number of cells moved differs between fry and parr because fry are much smaller than parr. Fry that move cells randomly select one of the two cells surrounding their current location. For parr, the movement distance (MD) may be as great as three cells and depends on their current $\mu_{\text {pred }}$ risk (equation 28) or $p\left(C_{\max }\right)$ (equation 31), that is,

$$
\begin{aligned}
\mathrm{MD}_{\text {pred }} & =50 \times \mu_{\text {pred }} \\
\operatorname{MD}_{p\left(C_{\text {max }}\right)} & =3.0-\left[5.0 \times p\left(C_{\text {max }}\right)\right] .
\end{aligned}
$$

The individual parr moves whichever distance is greater, $\mathrm{MD}_{\text {pred }}$ or $\mathrm{MD}_{p\left(C_{\max }\right)}$. The logic behind both of these functions is that as conditions become poorer (either an increase in $\mu_{\text {pred }}$ or a decrease in $p\left[C_{\max }\right]$ ), individuals should move further. Kareiva and Odell (1987) used a similar logic in a model of simulated foraging and movement. The direction of movement, either upstream or downstream from the current location, is randomly determined.

For both fry and parr, individuals may not move beyond the bounds of the simulated Manistee River environment. Thus, individuals in the most upstream cell may only move downstream and those in the most downstream cell may only move upstream. We compared the results of simulations with this limitation with those of simulations that allowed individuals to wrap around the ends of the river and found no discernable difference in the final outputs. We opted for the limit to movement because it is simply more logical.

\section{Model Calibration and Baseline Simulation Results}

To calibrate and corroborate the model, we focused on fitting vital statistics (growth and mortality), population abundances, and stage durations to literature values for as many stages as possible. The simulation experiments (described below) varied water temperature, total daily water discharge, and the initial number of spawning females. We set baseline values for these variables to replicate the current conditions observed in the Manistee River. Those for water temperature are the long-term mean value with the simulated daily variance generated by the model (Figure 1). Those for daily total water discharge are the 9-year mean with daily variance generated by the model (Figure 2b). The number of spawning females is set to 3,000, which is consistent with the adult spawner harvest in the Manistee River and the number of spawning females (24 redds/ha; range $=0.3-68.0)$ found in the nearby Pere Marquette River (Workman 2002). All model simulations were run on a Dell Precision 670 workstation using dual Xeon processors, resulting in an average run time of $13 \mathrm{~min}$ for baseline simulations.

The baseline simulations produced durations and mortality rates for the egg and alevin stages (Table 1) that correspond well with literature values. The mean 


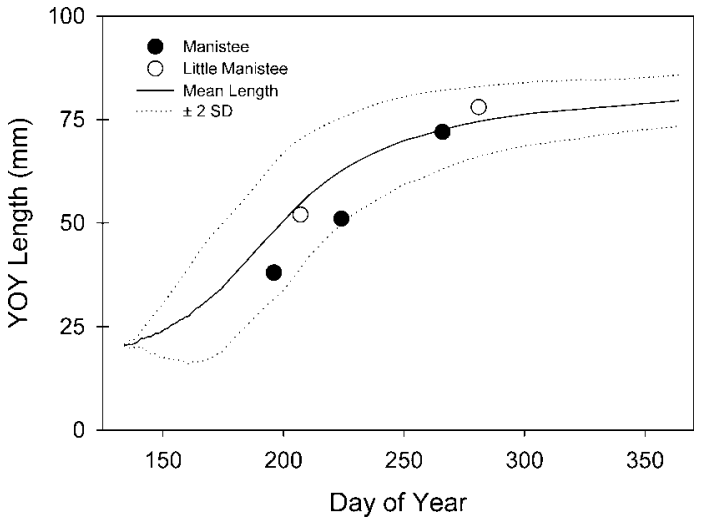

FIGURE 5.- Mean length of age-0 (YOY) steelhead (fry and parr) \pm 2 SDs in one randomly selected baseline population simulation relative to the observed lengths of age-0 fish collected in the Manistee and Little Manistee rivers (Woldt and Rutherford 2002).

duration for the egg stage in the five baseline simulations was about $35 \mathrm{~d}$, which is very close to that reported for eggs $(33 \mathrm{~d})$ raised in an laboratory setting (Nagler et al. 2000). The mean duration of the alevin stage $(7 \mathrm{~d})$ is shorter than that reported by Nagler et al. $(2000 ; 15$ d) but consistent with that reported by Kamler (1992). Data on egg and alevin mortality rates are rare; however, the rates reported here (Table 1) are consistent with those of earlier models (Van Winkle et al. 1998; Clark and Rose 1997) at 0.03 per day. The period during which simulated eggs are spawned and developing in the redd is consistent with data for steelhead in Great Lakes tributaries (Biette et al. 1981).

We compared parr length at date, mortality rate, and density with data from the Manistee and Little Manistee rivers (Woldt and Rutherford 2002) for calibration and corroboration. The simulated lengths of age-0 steelhead (fry and parr) reasonably fit data from the two rivers (Figure 5). For length calibration, we combine simulated fry and parr because differentiation between the two size-classes in the field is difficult and subjective (D. Swank, University of Michigan, personal communication), whereas model simulations allow for precise separation of the sizeclasses. Although there are few data on the growth of steelhead in these rivers, the final version of the model does reasonably replicate the growth observed in these two tributaries (Figure 5). The observed lengths of fry and parr fall within two standard deviations of the mean lengths computed for baseline simulations. Figure 5 shows the sizes for one baseline simulation, but length and its standard deviation differed little between baseline simulations. The estimated value of $Z$ for steelhead parr in the Manistee River in 1997 was

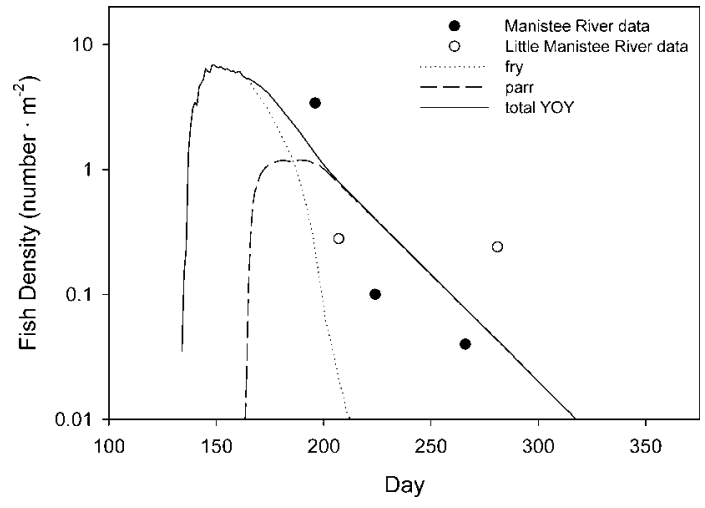

FIGURE 6.- Simulated densities of fry, parr, and all age-0 steelhead (fry plus parr) in a population model and the observed age- 0 density in the Manistee and Little Manistee rivers (Woldt and Rutherford 2002).

0.146 per day for 15 July to 12 August and 0.028 per day for 12 August to 23 September (Woldt and Rutherford 2002). The mean estimated value of $Z$ from the five baseline simulations was 0.0561 per day for fry and 0.0443 per day for parr, which fall within the range of the observed rates. The densities of parr and fry in the baseline simulations fit the observed data from the Manistee and Little Manistee rivers fairly well (Figure 6). Although we feel confident of the model calibration, the model will simulate only changes from baseline conditions rather than the actual parr numbers produced.

\section{Simulation Experiments}

For this analysis, we conducted two sets of simulation experiments to determine how changes to the steelhead population and to the Manistee River affect steelhead population dynamics. For both simulation experiments, we analyze model output of the number and mean weight of parr produced by the end of the first growing season (2 October [day 275]). Hereafter, we refer to the number of parr produced by the end of the first growing season simply as the parr number. For specific sets of simulations, we analyze survival through each stage to gain a better understanding of the processes that cause changes in parr number. The first simulation experiment evaluates the effect of a wide range of levels in the three main factors of interest: the number of spawning females, the temperature regime in the river, and the total discharge from Tippy Dam. The second simulation experiment is a full factorial design intended to determine the importance of interactions between the main factors. 


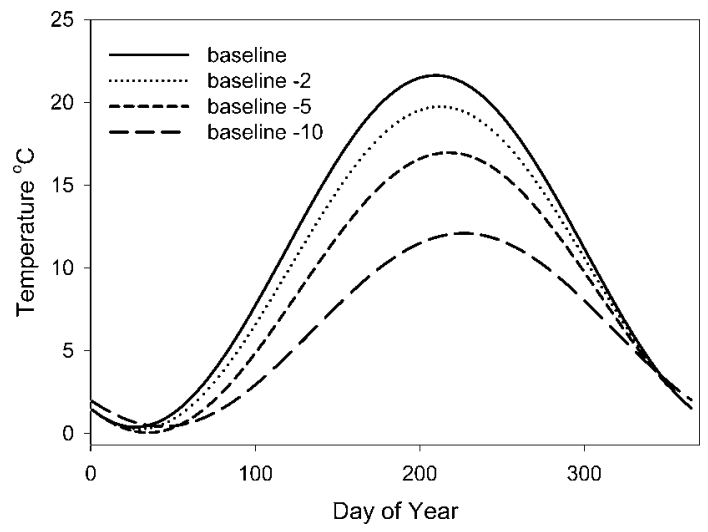

FiguRE 7.-Mean daily water temperatures for Manistee River simulations involving midsummer temperature reductions of 2,5 , and $10^{\circ} \mathrm{C}$. Each simulation varied randomly from the mean shown here. Means were computed from equation (1) using the following parameter values: $a=10.0, b=8.5$, and $c=4.75$ for the baseline $-2^{\circ} \mathrm{C} ; a=8.5, b=7.0$, and $c=$ 4.75 for the baseline $-5^{\circ} \mathrm{C}$; and $a=6.25, b=4.25$, and $c=4.5$ for the baseline $-10^{\circ} \mathrm{C}$.

Main-factor simulations.-Because steelhead are still stocked in a number of tributaries and the Manistee River itself is a highly managed environment, we elected to examine the effect of three variables that are subject to management decisions: the number of spawning females, water temperature, and total water discharge. In the Manistee River, the number of spawning females will be affected by stocking decisions, and water temperature and total discharge will be affected by the operation of Tippy Dam. For all treatments in this simulation experiment, we ran five replicate simulations.

To analyze the effect of female spawner number on steelhead recruitment, we ran simulations with eight initial levels of spawning females. Estimates of the spawning female population for the Manistee River range from 1,500 to 10,000 (median, 3,000; Fielder 1987). Therefore, in our simulations we used 500, $1,000,2000, \ldots, 7,000$ to capture the approximate range from the field data, and we used a baseline number $(3,000)$ based on those data.

The water temperature in the Manistee River may be affected by lowering the water intake at Tippy Dam (Horne et al. 2004). This would produce a reduction in the midsummer water temperature when the reservoir has a strong thermocline; however, in other seasons the water temperature would change little. To simulate the change in water temperatures that could result from a modification of Tippy Dam's water intake, we changed the mean water temperature computed using equation (1) so that winter temperatures would remain the same but midsummer temperatures would decrease by 2,5 , and $10^{\circ} \mathrm{C}$ (Figure 7). For each simulation, the actual daily water temperature varies randomly. We selected these changes because they capture the full range of possible changes in the Manistee River, although, a $10^{\circ} \mathrm{C}$ decrease is probably not feasible.

Water discharge changes are modeled simply for these simulations. Total discharge (Figure 2) is increased or decreased from baseline levels by the same multiplier for all days in the simulation. This generates an overall change in the total amount of water in the river. In these simulations, we used discharge multipliers of $0.50,0.75,1.00$ (baseline), $1.25,1.50$, and 1.75. An analysis of USGS gauge data from 1940 to 1996 and from 1980 to 1996 indicates an average daily discharge of $30.37 \mathrm{~m}^{3} / \mathrm{s}$ and a range of 23.53-39.19 $\mathrm{m}^{3} / \mathrm{s}$, which corresponds to multipliers of 0.775-1.290. Our range of multipliers extends beyond the observed range to ensure that we detect effects of discharge in our model outputs.

Full factorial simulations.-We conducted a full factorial simulation experiment to determine whether any interactions between the main factors of spawner number, water temperature, and total discharge affected steelhead recruitment. We ran five replicate simulations of each of the following treatment combinations: four levels of spawning female number $(333,1,000,3,000$, and 9,000); the four levels of water temperature used in the first experiment (Figure 7); and five levels of discharge simulated as fractions $(0.50,0.75,1.00,1.25$ and 1.50) of the baseline. This results in 80 treatments and 400 simulations for the full factorial design.

To analyze the results of the full factorial experiment, we used an analysis of variance (ANOVA) but did not use $P$-values to determine the importance of the factors. Degrees of freedom may be made arbitrarily large in a simulation such as this. We consider a main effect or interaction important if it accounts for 5\% or more of the mean square error (MSE). This method of analysis has been used in previous simulation experiments (Tyler and Rose 1997).

\section{Sensitivity Analysis}

We conducted an individual parameter perturbation sensitivity analysis of six key parameters in the model. This analysis is similar to that conducted by Bartell et al. (1986) on the fish bioenergetics model. We increased and decreased the value of each selected parameter by a set percentage and then measured the resulting percentage change in model outputs. For this analysis, we increased or decreased each parameter by 2, 10, and 50\% and ran five simulations of each treatment. We analyzed the model outputs of parr 


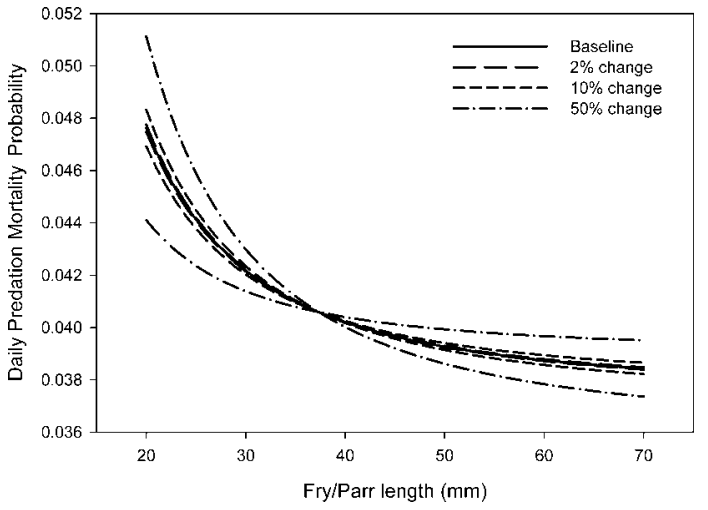

FIGURE 8.- - Length-based predation mortality for fry and parr steelhead used in the sensitivity analysis. Predation mortality uses the equation $\mu_{\text {pred }}=a+b\left(L^{-1.9}\right)$ (equation 27). Parameters $a$ and $b$ were modified to adjust the effect of steelhead length on predation mortality for the sensitivity analysis: $2 \%$ increase: $a=3.06, b=0.03744 ; 2 \%$ decrease: $a=$ $2.94, b=0.03756 ; 10 \%$ increase: $a=3.3, b=0.03719 ; 10 \%$ decrease: $a=2.7, b=0.03781 ; 50 \%$ increase: $a=4.5, b=$ $0.03595 ; 50 \%$ decrease: $a=1.5, b=0.03905$. Increases in the effect of fry and parr length on predation mortality result in predation rates that are higher than baseline at lengths less than $38 \mathrm{~mm}$ and lower than baseline for lengths greater than $38 \mathrm{~mm}$. The opposite is true for decreases in the effect of fry and parr length on predation mortality. The lines for $2 \%$ changes in the effect of length on fry and parr predation mortality largely overlap the baseline and thus are difficult to distinguish.

number and mean parr weight at the end of each simulation (day 275).

For this analysis, we opted to examine the effect of six parameters on model outputs: PD (equation 6), RD (equation 22), memory factor (equations 30 and 31), effect of length on fry and parr predation mortality (equation 27), fry station density, and parr station density. These parameters were selected because they affect different biological components in the model and there is some degree of uncertainty associated with each of them. Prey density defines total food availability, RD affects fish foraging, the memory factor affects individual movement decisions, the effect of length on predation mortality affects survival, and the density of feeding stations affects the intensity of dominance interactions as well as feeding and survival.

Executing the parameter changes in the model generally required application of an appropriate multiplier to the parameter value (e.g., for the $10 \%$ increase treatment, the multiplier was 1.10) for each day (e.g., PD) or to the value for each individual (e.g., RD). To achieve the changes in the effect of length on predation mortality, we adjusted the values of the

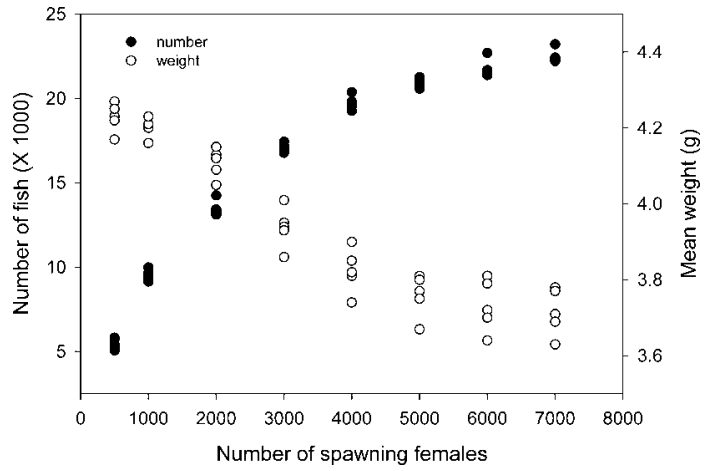

FIGURE 9.-Changes in the number and mean weight of steelhead parr as the number of spawning females changes from its baseline $(3,000)$, as simulated for the Manistee River population.

constant (0.0375) and length multiplier (3.0) in equation (27) while keeping the exponent $(-1.9)$ the same (Figure 8). In making these adjustments, the overall predation probability for $20-70-\mathrm{mm}$ fish was kept constant to isolate the length effect on predation mortality rather than simply altering the overall predation effect.

\section{Results}

\section{Main-Factor Simulations}

The main-factor simulations show differences in parr number and parr mean weight resulting from changes in the number of female spawners, midsummer maximum water temperature, and total discharge. Parr number increased as the number of spawning females increased, and parr mean weight decreased as parr number increased (Figure 9).

Reducing the maximum midsummer water temperature in the simulated Manistee River produced an increase in parr number for every temperature regime change (Figure 10), although the increase for simulated decreases of $2^{\circ} \mathrm{C}$ was fairly trivial. Reducing the maximum midsummer temperature by $5^{\circ} \mathrm{C}$ resulted in a notable increase in parr number, but by far the greatest effect of temperature on parr number occurred with a $10^{\circ} \mathrm{C}$ decrease.

The effect of changes in the temperature regime on parr weight was similar to that of parr number. The smallest reduction in maximum midsummer temperature had no noticeable effect on mean weight; the $5^{\circ} \mathrm{C}$ reduction had some effect. The $10^{\circ} \mathrm{C}$ decrease clearly had the largest effect on parr weight (Figure 10). A $10^{\circ} \mathrm{C}$ reduction in the maximum midsummer temperature also caused a notable decrease in two of the bioenergetic costs of growth (respiration and excretion) in the parr stage (Figure 11). The minimal reduction of 


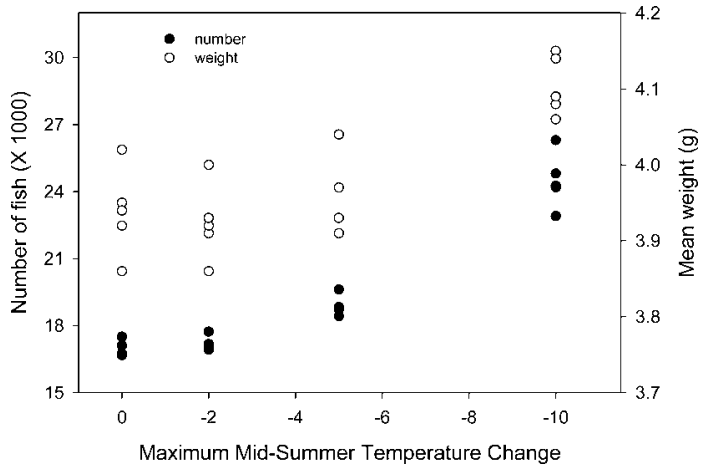

FiguRE 10.-Changes in the number and mean weight of steelhead parr as the maximum midsummer temperature decreases (baseline change $=0^{\circ} \mathrm{C}$ ), as simulated for the Manistee River population.

$2^{\circ} \mathrm{C}$ had no substantial effect on either respiration or excretion. The $5^{\circ} \mathrm{C}$ reduction affected these costs but not nearly as much as the $10^{\circ} \mathrm{C}$ reduction did. The costs of egestion and SDA showed no change in relation to reduced maximum midsummer temperature.
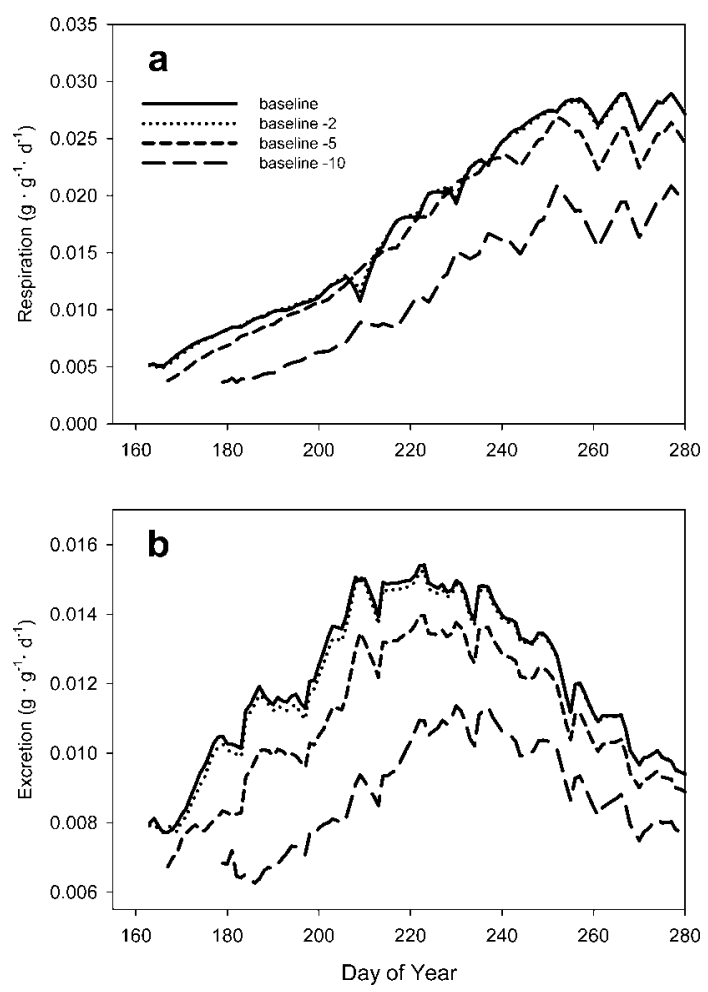

FiguRE 11.- Mean simulated values of (a) respiration and (b) excretion for steelhead parr in the Manistee River under different temperature regimes.

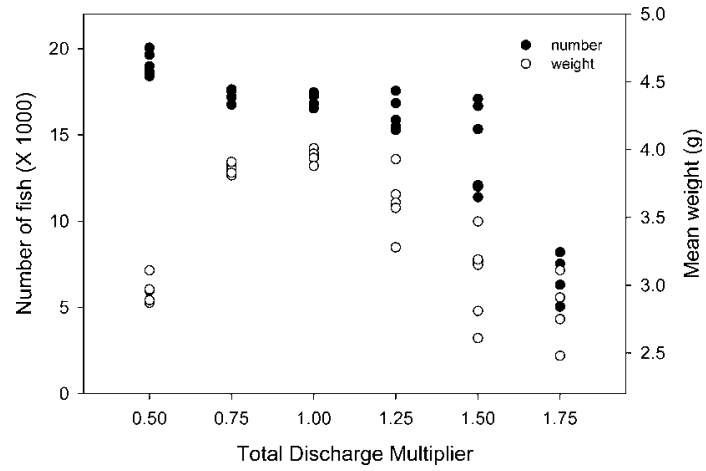

FIGURE 12.-Changes in the number and mean weight of steelhead parr as total water discharge from Tippy Dam varies, as simulated for the Manistee River population. Water discharges are expressed as multiples of the baseline discharge (1.0).

Changes in total discharge in the simulated Manistee River decreased parr number at levels above the baseline values (Figure 12). Changes in discharge below the baseline values had less effect, though the parr number increased for the lowest discharge. Every step increase above the baseline value decreased parr number in a linear fashion (regression for discharge values $\geq 1.0: R^{2}=0.712$ ). Parr mean weight was at a maximum at the baseline discharge and declined with positive or negative deviations from the baseline (Figure 12)

\section{Full Factorial Simulations}

Analysis of the full factorial experiment indicates that each of the three main effects (spawning female number, water temperature, and total discharge) accounted for an important fraction of the variation in parr number and parr weight (Table 2). Spawning female number accounted for the greatest amount of variation in parr number $(80 \%)$, but total discharge accounted for the greatest amount of variation in parr mean weight (76\%). Combining parr number and mean weight to obtain total parr biomass shows that although spawning female number and water discharge both account for important amounts of the variability in biomass, female number accounts for the greater share. Water temperature and total discharge each accounted for about $8 \%$ of the variance in parr number. Water temperature accounted for an insignificant amount of variance in mean weight but an important amount of the variation in biomass $(9 \%)$. The variability in parr number, mean weight, or biomass was not well described by any of the interactions.

To determine the relative importance of the two environmental variables (total discharge and water 
TABLE 2.- Results of ANOVA of the full factorial experiment, showing the effects of various factors on the number of steelhead parr reaching the end of the growing season, mean parr weight, total parr biomass, and the number of fry that survived to become parr in a simulated population. Factors accounting for 5\% or more of the mean square error (MSE) in a simulated population are indicated by bold italics.

\begin{tabular}{|c|c|c|c|c|c|c|}
\hline \multirow[b]{2}{*}{ Factor } & \multicolumn{2}{|c|}{ Number } & \multicolumn{2}{|c|}{ Mean weight (g) } & \multicolumn{2}{|c|}{ Biomass (g) } \\
\hline & MSE & $\%$ MSE & MSE & $\%$ MSE & MSE & $\%$ MSE \\
\hline Spawning females $(S)$ & $6.66 \times 10^{9}$ & 79.76 & 5.53 & 19.37 & $6.01 \times 10^{10}$ & 70.39 \\
\hline Water temperature $(T)$ & $7.03 \times 10^{8}$ & 8.42 & 0.06 & 0.21 & $7.83 \times 10^{9}$ & 9.18 \\
\hline Total discharge $(D)$ & $7.19 \times 10^{8}$ & 8.61 & 21.79 & 76.29 & $1.40 \times 10^{10}$ & 16.45 \\
\hline$S \times T$ & $1.32 \times 10^{8}$ & 1.58 & 0.01 & 0.02 & $1.20 \times 10^{9}$ & 1.41 \\
\hline$S \times D$ & $1.18 \times 10^{8}$ & 1.42 & 1.13 & 3.94 & $1.89 \times 10^{9}$ & 2.22 \\
\hline$T \times D$ & $1.18 \times 10^{7}$ & 0.14 & 0.02 & 0.07 & $2.43 \times 10^{8}$ & 0.28 \\
\hline$S \times T \times D$ & $4.39 \times 10^{6}$ & 0.05 & 0.004 & 0.01 & $5.68 \times 10^{7}$ & 0.07 \\
\hline Error & $1.93 \times 16^{7}$ & 0.02 & 0.02 & 0.08 & $7.85 \times 10^{6}$ & 0.01 \\
\hline Factor total & $2.164 \times 10^{11}$ & & 40.015 & & $8.53 \times 10^{10}$ & \\
\hline
\end{tabular}

temperature) on parr number, we examined the adjusted $R^{2}$ values from models that included only a subset of the main factors (Table 3). As indicated in the analysis of the full factorial experiment, the number of spawning females accounts for the greatest amount of variability in parr number. Adding either of the environmental variables increases the amount of variability explained by the model, and the increase is greater when water temperature is added to the model (0.0667) than when water discharge is added (0.0529). A similar analysis of the effects of the three main factors on biomass gave corresponding results; the number of spawning females accounted for the greatest amount of variability in biomass, and water temperature explained the second highest amount (Table 3). For both parr number and biomass, total discharge accounted for a smaller amount of the variance than did the other factors.

A stepwise variable selection analysis of the effects of the three main factors on parr mean weight showed that only the number of spawning females and total discharge accounted for significant amounts of variability in the data. In combination, the two significant factors explained much less of the variability in weight (adjusted $R^{2}=0.2494$ ) than of that in parr number or biomass. Water temperature was not an important variable (partial correlation $=0.0174)$.

\section{Analyzing Stage Data}

The factorial simulation experiment shows that the number of spawning females explains the most variance in parr number. In addition, the main-factor experiment shows classic density dependence in parr number in relation to spawning female number. To assess which life history stage or stages caused this limit, we plotted the number of individuals entering and surviving each of four life stages in main-factor simulations that adjusted spawning female number
(Figure 13). We found a linear response in the number of individuals entering and leaving the egg, alevin, and parr stages. There was, however, an upper limit to the number leaving the fry stage (about 1.1 million), suggesting that this stage is responsible for the upper limit on parr number (Figure 9). However, this cannot be taken as evidence that a limit does not exist for the parr stage, because the number of individuals that enter the parr stage is limited in the fry stage.

An ANOVA conducted on survival (the fraction of individuals entering the stage that survived to the end of the stage) through the four life stages in the full factorial experiment supports some important findings but presents other, unexpected, findings. Only main effects (number of spawning females, water temperature, and total discharge) account for an important fraction of the variability in survival through any of the stages (Table 4). The number of spawning females affected survival through the fry stage, providing further support for fry density dependence as observed in Figure 13. As expected, water temperature had the greatest effect on survival through the egg and alevin stages, and total discharge had an important, but smaller effect. All three main effects influenced survival through the fry stage, the number of spawning females having the greatest effect (Table 4). Survival

TABLE 3.-Adjusted $R^{2}$ values used to select factors affecting steelhead parr number and survival through the combined fry and parr stages in a simulated population.

\begin{tabular}{llc}
\hline & \multicolumn{2}{c}{ Adjusted $R^{2}$} \\
\cline { 2 - 3 } Factor(s) & Parr number & Biomass \\
\hline Spawning females & 0.663 & 0.578 \\
Spawning females and water temperature & 0.729 & 0.650 \\
Spawning females and total discharge & 0.715 & 0.644 \\
Spawning females, water temperature, & 0.782 & 0.693 \\
$\quad$ and total discharge & & \\
\hline
\end{tabular}



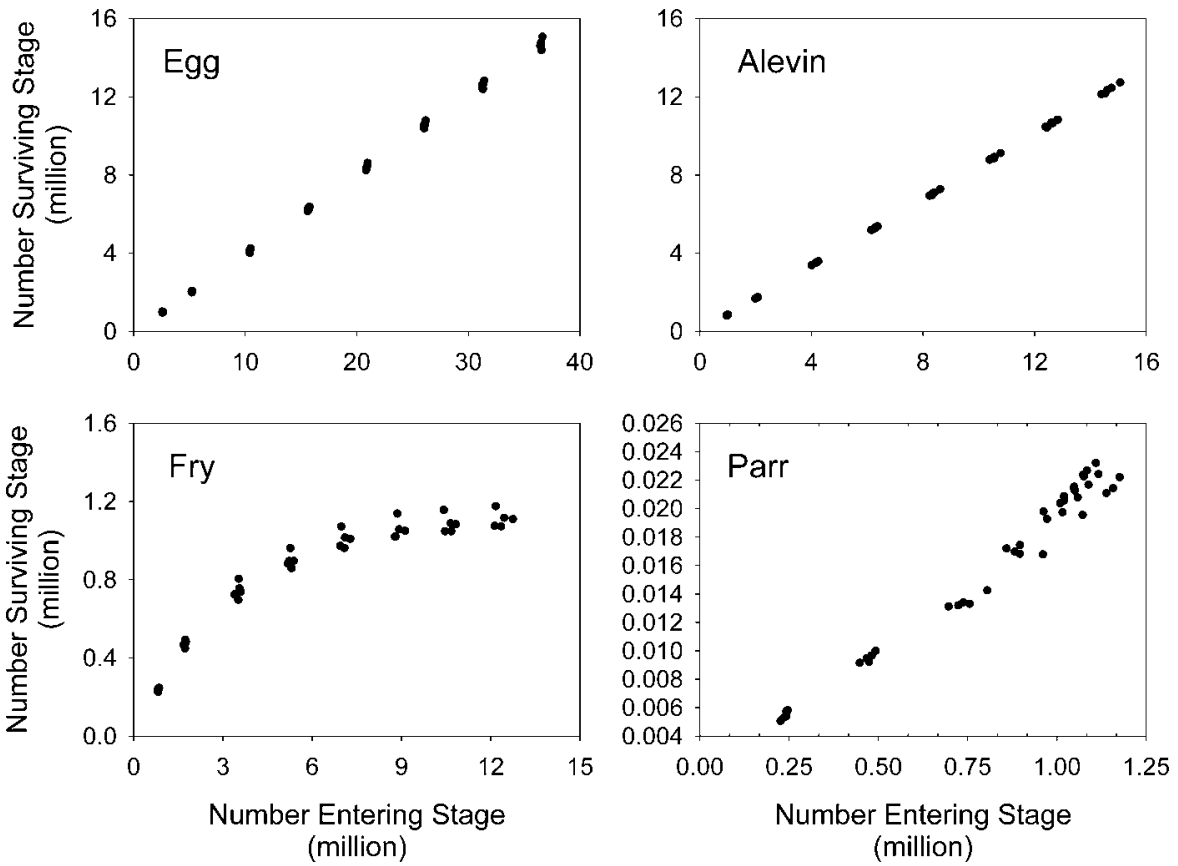

FIGURE 13.- Number of steelhead entering and surviving the egg, alevin, fry, and parr stages in a main-factor simulation experiment examining the effect of changes in the number of spawning females in the Manistee River.

through the parr stage was affected most by water temperature and less by total discharge. Again, because of the effect of density on survival through the fry stage, this analysis cannot detect an effect of density on parr survival.

The ANOVA indicates the factors with important effects on stage survival but not the direction of the effects. Because no interactions between factors affected stage survival, we plotted stage survival from the main-factor simulations in relation to water temperature and total discharge. Decreases in the maximum midsummer water temperature caused a decrease in survival through the egg and alevin stages but increased survival through the fry and parr stages (Figure 14). The finding in the ANOVA that total discharge mostly affects fry and parr survival (Table 4) is further supported by graphs of the relationships (Figure 15). Total discharge accounted for a large amount of the variability in fry and parr survival, but the two stages experience opposite effects. Increased discharge generally decreased survival through the fry stage but generally increased survival through the parr stage (Figure 15). Although an increase in total discharge nearly doubled parr survival, the decrease in fry survival over the same range of total discharge

TABLE 4.- Results of ANOVA of full factorial simulation experiment, showing the effect of various factors on steelhead survival through each of four life stages. Factors accounting for $5 \%$ or more of the mean square error (MSE) are indicated by bold italics.

\begin{tabular}{|c|c|c|c|c|c|c|c|c|}
\hline \multirow[b]{2}{*}{ Factor } & \multicolumn{2}{|l|}{ Egg } & \multicolumn{2}{|c|}{ Alevin } & \multicolumn{2}{|l|}{ Fry } & \multicolumn{2}{|l|}{ Parr } \\
\hline & MSE & $\%$ MSE & MSE & $\%$ MSE & MSE & $\%$ MSE & MSE & $\%$ MSE \\
\hline Spawning females $(S)$ & $7.86 \times 10^{-3}$ & 2.44 & $8.00 \times 10^{-5}$ & 0.17 & 0.469 & 76.07 & $2.10 \times 10^{-4}$ & 2.11 \\
\hline Water temperature $(T)$ & 0.177 & 55.01 & 0.041 & 87.42 & 0.036 & 5.78 & $5.01 \times 10^{-3}$ & 50.26 \\
\hline Total discharge $(D)$ & 0.121 & 37.61 & $3.75 \times 10^{-3}$ & 8.04 & 0.096 & 15.54 & $3.78 \times 10^{-3}$ & 37.92 \\
\hline$S \times T$ & $5.00 \times 10^{-5}$ & 0.02 & $1.00 \times 10^{-5}$ & 0.02 & $5.00 \times 10^{-4}$ & 0.08 & $4.72 \times 10^{-6}$ & 0.05 \\
\hline$S \times D$ & $4.80 \times 10^{-4}$ & 0.15 & $7.00 \times 10^{-5}$ & 0.15 & 0.012 & 1.97 & $7.28 \times 10^{-4}$ & 7.30 \\
\hline$T \times D$ & $4.60 \times 10^{-4}$ & 0.14 & $5.00 \times 10^{-5}$ & 0.11 & $3.20 \times 10^{-4}$ & 0.05 & $8.73 \times 10^{-5}$ & 0.88 \\
\hline$S \times T \times D$ & $1.00 \times 10^{-5}$ & 0.00 & $1.00 \times 10^{-5}$ & 0.02 & $1.00 \times 10^{-4}$ & 0.02 & $2.38 \times 10^{-5}$ & 0.24 \\
\hline Error & $8.20 \times 10^{-4}$ & 0.25 & $8.00 \times 10^{-5}$ & 0.17 & $2.10 \times 10^{-4}$ & 0.03 & $1.05 \times 10^{-5}$ & 0.11 \\
\hline Factor total & 0.322 & & 0.047 & & 0.616 & & $9.97 \times 10^{-3}$ & \\
\hline
\end{tabular}



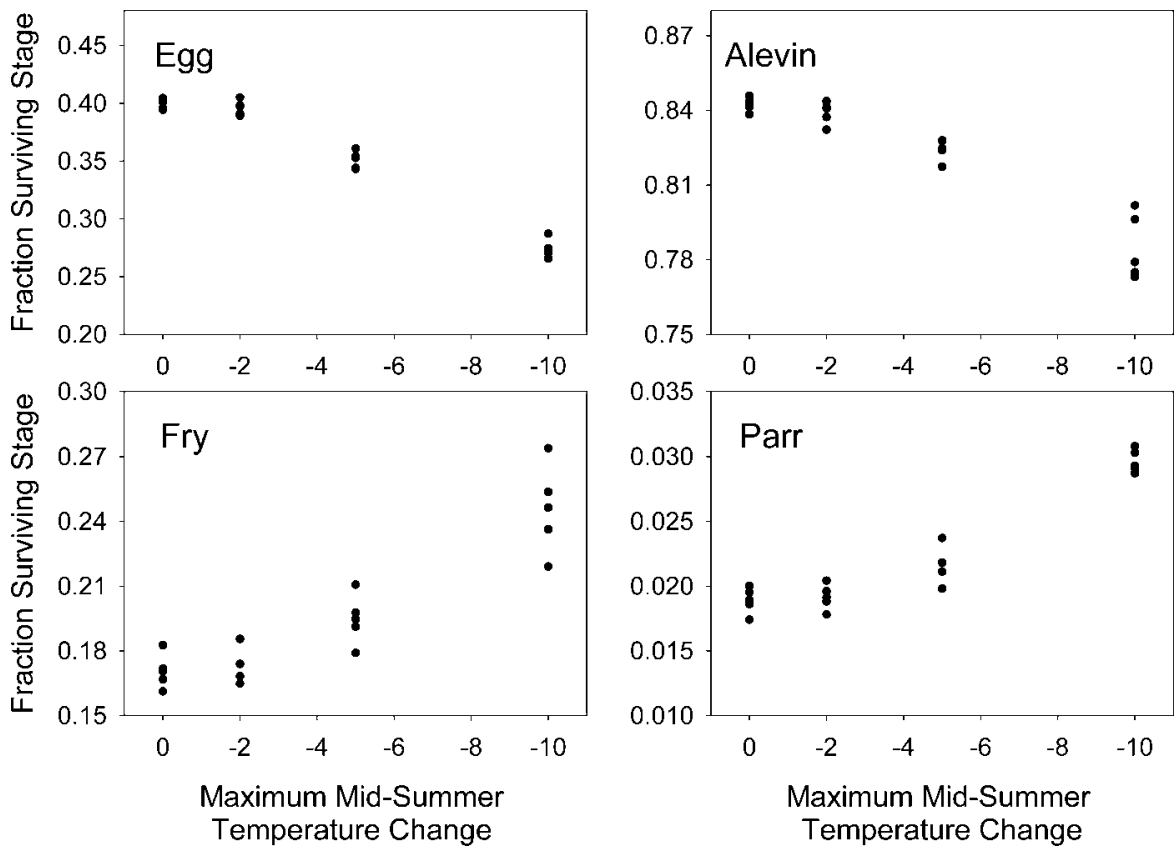

FIGURE 14.- Survival of steelhead through the egg, alevin, fry, and parr stages in relation to simulated reductions of 2, 5, and $10^{\circ} \mathrm{C}$ from the baseline maximum midsummer water temperature in the Manistee River.
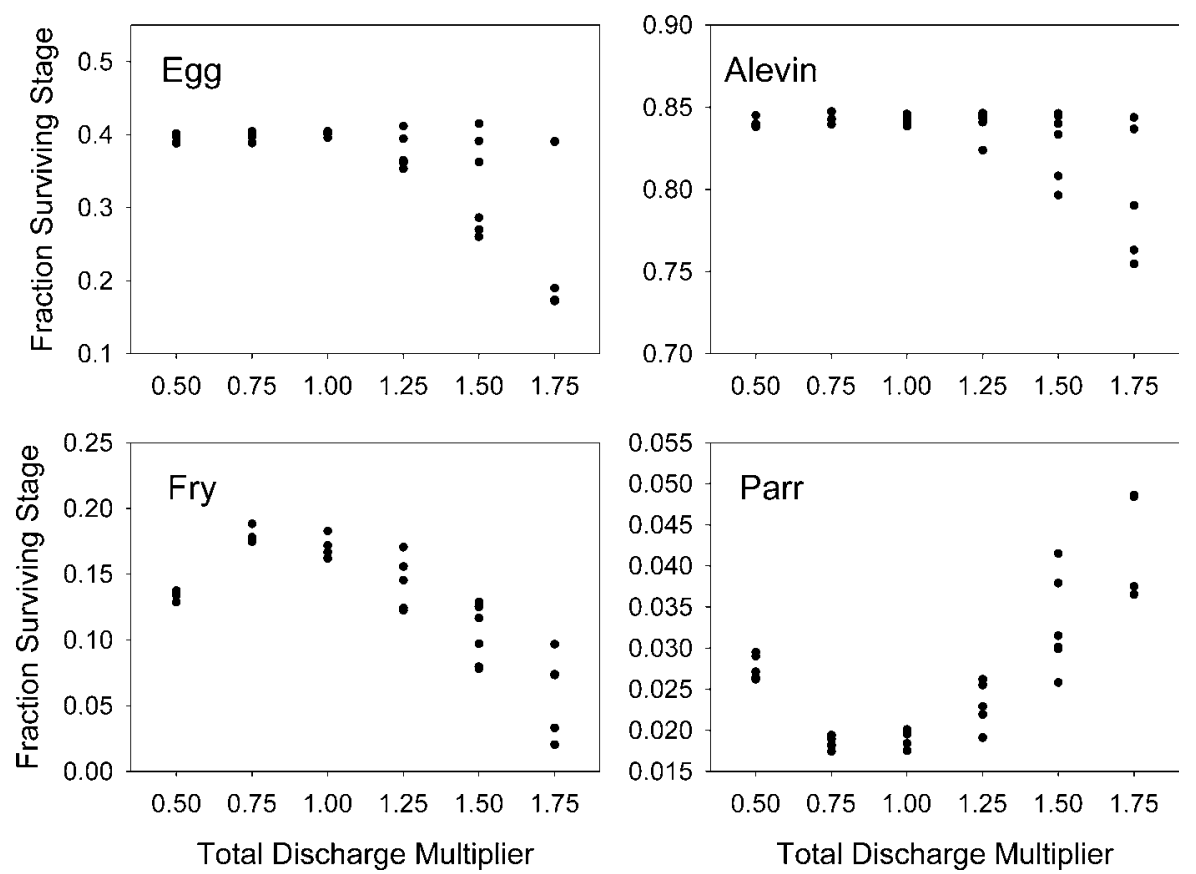

FIGURE 15.- Survival of steelhead through the egg, alevin, fry, and parr stages in relation to simulated changes in total water discharge from Tippy Dam. Water discharges are expressed as multiples of the baseline discharge (1.0). 

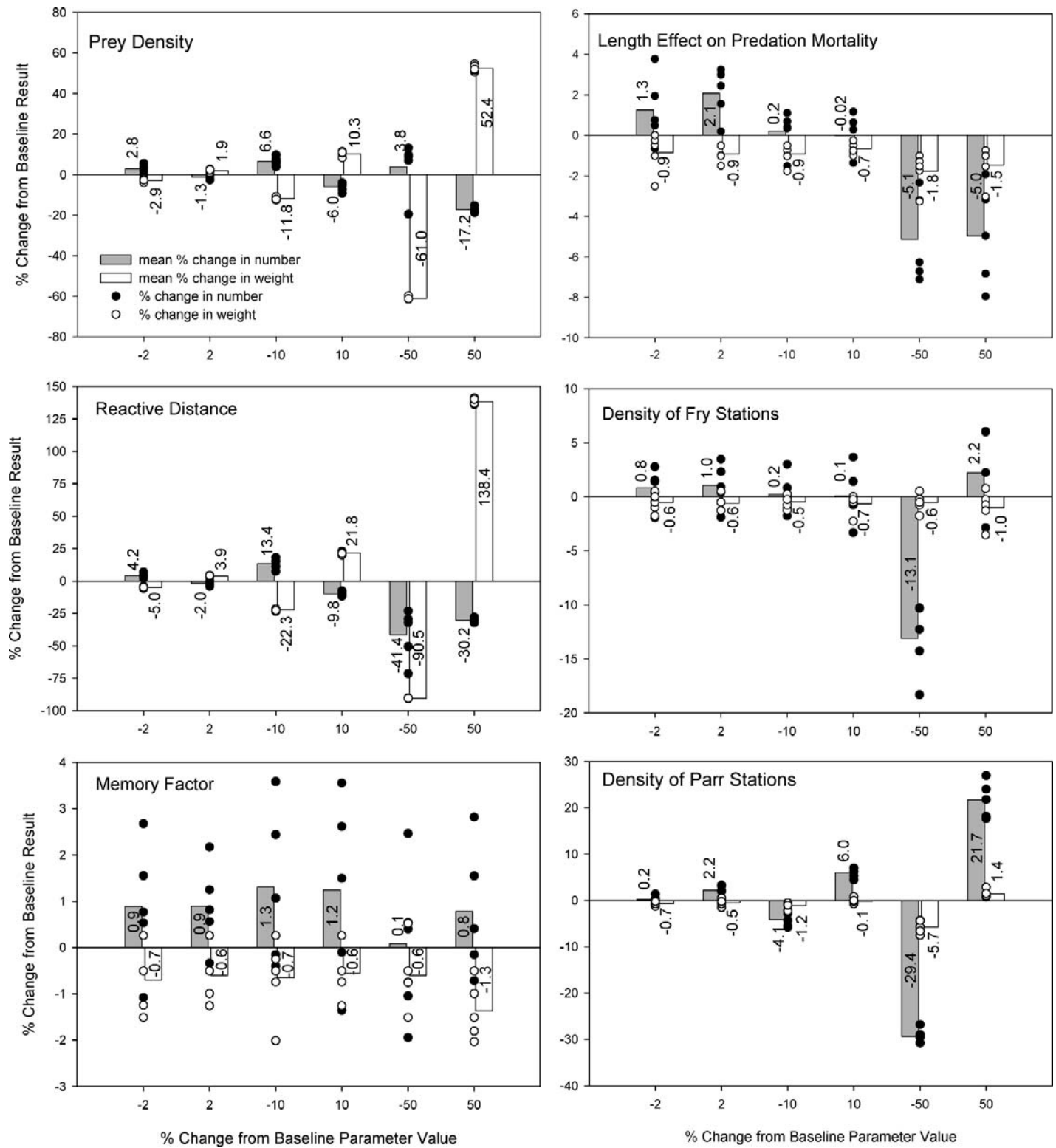

FIGURE 16.- Results of the steelhead population model sensitivity analysis, showing the percentage changes from the baseline results in the number and weight of parr at the end of the simulation (day 275) for given changes in parameter values from those used in the baseline. Actual means are shown with each bar. See text for an explanation of the variables examined.

was greater, resulting in the overall decrease in parr number as discharge increased (Figure 12).

\section{Sensitivity Analysis}

The results of the sensitivity analysis indicate that none of the parameters selected had an overwhelmingly important effect on parr number or final weight (Figure 16). Reactive distance was the only parameter for which a given percentage change resulted in an approximately equivalent or greater change in the model outputs. For all other parameters, the percentage change in model output was consistently much lower than that in the parameter value.

A ranking of the six parameters based on the average of the absolute value of the percentage change in model output provides insight into their relative importance 
TABLE 5.-Average rank of parameters according to percent change in steelhead parr number or weight in model sensitivity analysis. The lowest numbers (i.e., highest ranks) indicate the greatest average percent changes in number or weight at the end of the simulation. See text for an explanation of the variables used.

\begin{tabular}{lcc}
\hline \multicolumn{1}{c}{ Parameter } & Parr number & Parr weight \\
\hline Prey density & 3.0 & 2.0 \\
Reactive distance & 1.3 & 1.0 \\
Memory factor & 5.0 & 5.0 \\
Length effect on predation mortality & 4.0 & 3.3 \\
Density of fry stations & 4.8 & 5.2 \\
Density of parr stations & 2.8 & 4.5 \\
\hline
\end{tabular}

(Table 5). For both parr number and weight, RD had the highest rank among the parameters. Parr station density had the second highest rank in terms of its effect on parr number and was closely followed by PD. Prey density had the second highest rank in terms of its effect on parr weight, followed by the effect of length on predation mortality. The density of fry stations and memory factor had the smallest effects on parr number and weight.

The sensitivity analysis suggests a relationship between survival in the fry and parr stages as well as between parr number and parr weight. Density dependence in the fry or parr stage probably occurs because of the limited amount of feeding stations for each stage. Fry survival was positively related to the density of fry feeding stations (Table 6). However, for each change in fry survival, there was an opposite change in parr survival (Table 6). Secondly, Figure 16 shows an apparent relationship between parr number and weight at the end of the simulations. Of the 36 treatments, 28 show an opposite direction for the percentage change in parr number and weight, which is significant (sign test: $z=3.167)$. Thus, increases in parr number relative to the baseline correspond to decreases in parr weight, and decreases in parr number correspond to increases in parr weight.

\section{Discussion}

The simulation experiments show a strong effect of spawning female number on steelhead parr number with an upper limit of about 24,000 parr, indicating a classic case of density-dependent population growth. An examination of the numbers of individuals entering and surviving each stage (Figure 13) suggests that the fry stage poses an obvious limitation to parr production. However, the results from the sensitivity analysis suggest that the limitation on fry is mitigated somewhat in the parr stage, since decreases in fry survival correspond to increases in parr survival (Table 6). This inverse relationship between fry and parr survival is
TABLE 6.-Changes in steelhead fry and parr survival associated with changes in the density of fry or parr feeding stations in model sensitivity analysis.

\begin{tabular}{cccccc}
\hline & \multicolumn{2}{c}{ Fry station density } & & \multicolumn{2}{c}{ Parr station density } \\
\cline { 2 - 3 } \cline { 5 - 6 } $\begin{array}{c}\text { Change (\%) } \\
\text { from baseline }\end{array}$ & $\begin{array}{c}\text { Fry } \\
\text { survival }\end{array}$ & $\begin{array}{c}\text { Parr } \\
\text { survival }\end{array}$ & & $\begin{array}{c}\text { Fry } \\
\text { survival }\end{array}$ & $\begin{array}{c}\text { Parr } \\
\text { survival }\end{array}$ \\
\hline 0 & 0.1702 & 0.0194 & & 0.1702 & 0.0194 \\
-2 & 0.1681 & 0.0195 & & 0.1707 & 0.0191 \\
2 & 0.1725 & 0.0191 & & 0.1704 & 0.0196 \\
-10 & 0.1601 & 0.0204 & & 0.1702 & 0.0184 \\
10 & 0.1796 & 0.0182 & & 0.1706 & 0.0203 \\
-50 & 0.1077 & 0.0264 & & 0.1705 & 0.0135 \\
50 & 0.2141 & 0.0156 & & 0.1702 & 0.0233 \\
\hline
\end{tabular}

further supported by the observation that increased water discharge decreased fry survival while increasing parr survival (Figure 15). The inverse relationship also explains the low ranking of fry station density in the sensitivity analysis (Table 5). Any influence of fry station density was probably mitigated by changes in parr survival. The results from this simulation model provide support for both the fry stage (e.g., Elliott 1989 , 1993) and the parr stage (e.g., Grant and Kramer 1990; Grant et al. 1998) as the determinant of age-0 density.

Changes in total discharge and water temperature had about the same effect on parr number, but the effect of total discharge on parr biomass was notably greater that of water temperature (Table 2). Increases in total discharge resulted in faster water velocity in the river margin areas and thereby depressed steelhead growth and survival. In addition, the variability in both parr number and weight increased as water discharge increased (Figure 12). This finding suggests that one of the consequences of changes in total discharge is an increased sensitivity to heterogeneity in the habitat. At extreme levels of discharge, the importance of areas with unusual high or unusually low water velocity becomes exaggerated and there can be high variability in growth and survival.

In our model, the effect of changes in water temperature regime on steelhead production occurred when the maximum midsummer temperature was reduced by the greatest amount, namely, $10^{\circ} \mathrm{C}$. A modest $2^{\circ} \mathrm{C}$ reduction resulted in no effective difference in steelhead production, and a $5^{\circ} \mathrm{C}$ reduction caused only a small increase in parr number and had no effect on parr weight. These results can be explained by differences in the bioenergetic costs of growth. Respiration and excretion costs were considerably lower when the maximum midsummer temperature was reduced by $10^{\circ} \mathrm{C}$; these costs differed little from baseline conditions when the maximum midsummer temperature was reduced by only $2^{\circ} \mathrm{C}$ or $5^{\circ} \mathrm{C}$ (Figure 11). Horne et al. (2004) showed that a small 
temperature change can be achieved in the Manistee River by changing the location of the water intake for Tippy Dam. They found that a $5^{\circ} \mathrm{C}$ or $10^{\circ} \mathrm{C}$ reduction in midsummer tailrace temperature was not possible through manipulations of Tippy Dam water intake. Survival for fry and parr stages increased as water temperature decreased, which implies that stocking of small steelhead in the Manistee River would have greater success under a substantially cooler temperature regime.

The sensitivity analysis indicates that none of the parameters examined has an excessive influence on parr number or weight. Changes in the parameter with the greatest influence, $\mathrm{RD}$, resulted in model output changes of approximately the same magnitude (e.g., a $10 \%$ increase in RD corresponded to a $-9.8 \%$ decrease in parr number). Reactive distance is expected to have the greatest effect on parr number because of its nonlinear influence on fry and parr consumption: volume searched is a function of $\mathrm{RD}^{2}$ (equation 22). When one perturbs individual parameters, those that are nonlinearly related to model functions are expected to have a greater influence on model outputs than are linearly related parameters (Bartell et al. 1986).

The findings from this work provide some information that may be useful for managers of steelhead populations in rivers such as the Manistee River. Density limitations and survival reductions from increased total discharge occur in both the fry and parr stages. Decisions on how large to grow fish for stocking may well depend on the availability of habitat for the life stage at which the fish will be stocked. Managers should not assume that fry habitat is unlimited and that only parr habitat need be considered in stocking decisions.

Restoring a natural flow regime to the Manistee River probably will enhance it as a habitat for fish populations. The construction of Tippy and Hodenpyl dams has vastly changed the Manistee River flow regime; however, the dams are not the only cause of flow regime change. Human development and changes in land use in the watershed have altered the amount of surface runoff, which in turn has altered the total discharge, variability in discharge, and water temperature (Poff et al. 1997). Our simulations show that the increases in total discharge and water temperature stemming from land use changes can easily lead to lower steelhead numbers in the Manistee River and similar rivers.

The analysis presented in this paper identifies river discharge as an important environmental variable affecting steelhead populations in the Manistee River; however, the approach used for manipulating total discharge is simplistic. Our results suggest that a more thorough analysis of the effects of historical changes in flow regime on steelhead populations would be valuable.

\section{Acknowledgments}

This work benefited from the efforts and advice of M. Wiley, C. Riseng, S. Creque, D. Swank, and L. Hinz at the University of Michigan and M. Bolduc, C. Goller, P. Mathisen, and J. Wilbur at Worcester Polytechnic Institute. This research also benefited from funding by the Great Lakes Fishery Trust and Great Lakes Protection Fund.

\section{References}

Babbitt, B. 2002. What goes up may come down. BioScience 52:656-658.

Bartell, S. M., J. E. Breck, R. H. Gardner, and A. L. Brenkert. 1986. Individual parameter perturbation and error analysis of fish bioenergetics models. Canadian Journal of Fisheries and Aquatic Sciences 43:160-168.

Bernstein, C., A. C. Kacelnik, and J. R. Krebs. 1988. Individual decisions and the distribution of predators in a patchy environment. Journal of Animal Ecology 57:1007-1026.

Biette, R. M., D. P. Dodge, R. L. Hassinger, and T. M. Stauffer. 1981. Life history and timing of migrations and spawning behavior of rainbow trout (Salmo gairdneri) populations in the Great Lakes. Canadian Journal of Fisheries and Aquatic Sciences 38:1759-1771.

Brock, T. D. 1981. Calculating solar radiation for ecological studies. Ecological Modelling 8:109-132.

Bunn, S. E., and A. H. Arthington. 2002. Basic principles and ecological consequences of altered flow regimes for aquatic biodiversity. Environmental Management 30:492-507.

Charnov, E. L. 1976. Optimal foraging, the marginal value theorem. Theoretical Population Biology 9:129-136.

Church, M. A., D. G. McLean, and J. F. Wolcott. 1987. Sediment transfer in gravel-bed rivers. Wiley, New York.

Clark, M. E., and K. A. Rose. 1997. Factors affecting competitive dominance of rainbow trout over brook trout in southern Appalachian streams: implications of an individual-based model. Transactions of the American Fisheries Society 126:1-20.

Crisp, D. T., and P. A. Carling. 1989. Observations on siting, dimensions, and structure of salmonid redds. Journal of Fish Biology 34:119-134.

Elliott, J. M. 1989. Mechanisms responsible for population regulation in young migratory trout, Salmo trutta, I. The critical time for survival. Journal of Animal Ecology 58:987-1001.

Elliott, J. M. 1993. The self-thinning rule applied to juvenile sea-trout, Salmo trutta. Journal of Animal Ecology 62:371-379.

Fielder, D. G. 1987. An assessment of the introduction of summer steelhead into Michigan. Michigan Department of Natural Resources, Fisheries Research Report 1948, Ann Arbor.

Freeman, M. C., Z. H. Bowen, K. D. Bovee, and E. R. Irwin. 2001. Flow and habitat effects on juvenile fish 
abundance in natural and altered flow regimes. Ecological Applications 11:179-190.

Gerritsen, J., and J. R. Strickler. 1977. Encounter probabilities and community structure in zooplankton: a mathematical model. Journal of the Fisheries Research Board of Canada 34:73-82.

Gilliam, J. F., and D. F. Fraser. 1987. Habitat selection under predation hazard: test of a model with foraging minnows. Ecology 68:1856-1862.

Godby, N. A., Jr. 2000. Growth, diet, and prey availability for juvenile steelhead in Muskegon River, Michigan. Master's thesis. University of Michigan, Ann Arbor.

Godin, J.-G., and R. Rangeley. 1989. Living in the fast lane: effects of cost of locomotion on foraging behavior in juvenile Atlantic salmon. Animal Behaviour 37:943-954.

Grant, J. W. A., and D. L. Kramer. 1990. Territory size as a predictor of the upper limit to population density of juvenile salmonids in streams. Canadian Journal of Fisheries and Aquatic Sciences 47:1724-1737.

Grant, J. W. A., and D. L. G. Noakes. 1987. A simple model of optimal territory size for drift-feeding fish. Canadian Journal of Zoology 65:270-276.

Grant, J. W. A., S. O. Steingrimsson, E. R. Keeley, and R. A. Cunjak. 1998. Implications of territory size for the measurement and prediction of salmonid abundance in streams. Canadian Journal of Fisheries and Aquatic Sciences 55:181-190.

Hanson, P. C., T. B. Johnson, D. E. Schindler, and J. F Kitchell. 1997. Fish bioenergetics 3.0. University of Wisconsin, Sea Grant Institute, Madison.

Hart, D. D., T. E. Johnson, K. L. Bushaw-Newton, R. J. Horwitz, A. T. Bednarek, D. F. Charles, D. A. Kreeger, and D. J. Velinsky. 2002. Dam removal: challenges and opportunities for ecological research and river restoration. BioScience 52:669-681.

Hill, J., and G. D. Grossman. 1993. An energetic model of microhabitat use for rainbow trout and rosyside dace. Ecology 74:685-698.

Hokanson, K. E. F., C. F. Kleiner, and T. W. Thorslund. 1977. Effects of constant temperatures and diel temperature fluctuations on specific growth and mortality rates and yield of juvenile rainbow trout, Salmo gairdneri. Journal of the Fisheries Research Board of Canada 34:639-948.

Horne, B. D., E. S. Rutherford, and K. H. Wehrly. 2004. Simulating effects of hydro-dam alteration on the thermal temperature regime and wild steelhead recruitment in the Manistee River, Michigan. River Research and Applications 20:185-203.

Hughes, N. F., and L. M. Dill. 1990. Position choice by driftfeeding salmonids: model and test for Arctic grayling (Thymallus arcticus) in subarctic mountain streams, interior Alaska. Canadian Journal of Fisheries and Aquatic Sciences 47:2039-2048.

Ichthyological Associates. 1990. Instream flow incremental methodology: hydraulic modeling report for the Tippy project, FERC Project 2580, Manistee River, Michigan. Report to Lawler, Matuskey, and Skelley, Engineers, contracted by Consumers Power Company, Lansing, Michigan.

Kamler, E. 1992. Early life history of fishes: an energetics approach. Chapman and Hall, London.

Kareiva, P. M., and G. Odell. 1987. Swarms of predators exhibit "preytaxis" if individuals use area-restricted search. American Naturalist 130:233-270.

Kitchell, J. F., D. J. Stewart, and D. Weininger. 1977. Applications of a bioenergetics model to yellow perch (Perca flavescens) and walleye (Stizostedion vitreum vitreum). Journal of the Fisheries Research Board of Canada 34:1922-1935.

Lapointe, M., B. Eaton, S. Driscoll, and C. Latulippe. 2000. Modelling the probability of salmonid egg pocket scour due to floods. Canadian Journal of Fisheries and Aquatic Sciences 57:1120-1130.

Lytle, D. A., and N. L. Poff. 2004. Adaptation to natural flow regimes. Trends in Ecology and Evolution 19:94-100.

McCarthy, I. D., G. C. Carter, and D. F. Houlihan. 1992. The effect of feeding hierarchy on individual variability in daily feeding of rainbow trout, Oncorhynchus mykiss (Walbaum). Journal of Fish Biology 41:257-263.

Meyer, C. B. 2003. The importance of measuring biotic and abiotic factors in the lower egg pocket to predict coho salmon egg survival. Journal of Fish Biology 62:534548.

Milinski, M., and K. Regelmann. 1985. Fading short-term memory for patch quality in sticklebacks. Animal Behaviour 33:678-680.

Nagler, J. J., J. E. Parsons, and J. G. Cloud. 2000. Single-pair matings indicate maternal effects on embryo survival in rainbow trout, Oncorhynchus mykiss. Aquaculture 184:177-183.

Nakano, S. 1995. Individual differences in resource use, growth, and emigration under the influence of a dominance hierarchy in fluvial red-spotted masu salmon in a natural habitat. Journal of Animal Ecology 64:75-84.

Osmundson, D. B., R. J. Ryel, V. L. Lamarra, and J. Pitlick. 2002. Flow-sediment-biota relations: implications for river regulation effects on native fish abundance. Ecological Applications 12:1719-1739.

Poff, N. L., J. D. Allan, M. B. Bain, J. R. Karr, K. L. Prestegaard, B. D. Richter, R. E. Sparks, and J. C. Stromberg. 1997. The natural flow regime. BioScience 47:769-784

Rand, P. S., D. J. Stewart, P. W. Seelbach, and L. R. Wedge. 1993. Modeling steelhead population energetics in Lakes Michigan and Ontario. Transactions of the American Fisheries Society 122:977-1001.

Regier, H. A., J. A. Holmes, and D. Pauly. 1990. Influences of temperature changes on aquatic ecosystems: an interpretation of empirical data. Transactions of the American Fisheries Society 119:374-389.

Rose, K. A., J. A. Tyler, R. C. Chambers, G. Klein-MacPhee, and D. J. Danila. 1996. Simulating winter flounder population dynamics using coupled individual-based young-of-the-year and age-structured adult models. Canadian Journal of Fisheries and Aquatic Sciences 53:1071-1091.

Rozich, T. J. 1998. Manistee River assessment. Michigan Department of Natural Resources, Special Report 21, Ann Arbor.

Tyler, J. A., and M. B. Bolduc. In press. Individual variation in bioenergetic rates of YOY rainbow trout. Transactions of the American Fisheries Society.

Tyler, J. A., and K. A. Rose. 1997. Individual-based model of fish cohort growth, movement, and survival in a spatially 
explicit environment. Journal of Animal Ecology 66:122-136.

Van Winkle, W., H. I. Jager, S. F. Railsback, B. D. Holcomb, T. K. Studley, and J. E. Baldrige. 1998. Individual-based model of sympatric populations of brown and rainbow trout for instream flow assessment: model description and calibration. Ecological Modelling 110:175-207.

Werner, E. E., and J. F. Gilliam. 1984. The ontogenetic niche and species interactions in size-structured populations.
Annual Review of Ecology and Systematics 15: 393-425.

Woldt, A., and E. S. Rutherford. 2002. Production of juvenile steelhead in two central Lake Michigan tributaries. Michigan Department of Natural Resources, Fisheries Division Report 2060, Ann Arbor.

Workman, R. D. 2002. Spawning migrations and habitat selection by steelhead and longnose suckers in the Pere Marquette and St. Joseph rivers, Michigan. Doctoral dissertation. Michigan State University, East Lansing. 